\title{
Quantitative Measurement of the Influence of Degree of Saturation on Ion Penetration in Cement Paste by Using X-ray Imaging
}

\author{
Mehdi Khanzadeh Moradllo*, M. Tyler Ley \\ Department of Civil and Environmental Engineering, Oklahoma State University, Stillwater, OK, 74078, USA
}

\begin{abstract}
The external penetration of ions into concrete plays an important role in long-term durability of concrete structures. In addition, the degree of saturation (DoS) of the paste has a large impact on rate and mechanisms of fluid penetration into concrete. There is little knowledge of the dynamic process of fluid penetration into these materials because few experimental techniques are able to give quantitative spatial measurements of the fluid movement without damaging the sample. This paper uses laboratory transmission X-ray microscopy (TXM) to investigate the in-situ penetration of an iodide based tracer into cement paste with water-to-cement ratio of 0.40 conditioned at four different relative humidities (RH).

This technique can non-destructively image the distribution of the dissolved ions at $8.8 \mu \mathrm{m}$ resolution in minutes. In addition, micro X-ray fluorescence ( $\mu \mathrm{XRF})$ imaging and conventional gravimetric measurements were used to compare I and $\mathrm{Cl}$ penetration rate and validate the results from TXM. Mathematical models have been proposed to account for ion penetration in partially-saturated samples. The results show that samples that were ponded for two days after being conditioned in $35 \%$ and $70 \%$ RHs (DoS of $40.8 \%( \pm 0.1 \%)$ and $68.8 \%( \pm 0.5 \%)$ respectively) show a 40x and 10x increase respectively in the penetration coefficient over the saturated sample. Furthermore, important insights about combined ion transport mechanisms have been observed from concentration profiles by TXM.
\end{abstract}

Keywords: X-ray microscopy; Iodide; Chloride; Diffusion; Capillary absorption; Service life; Durability; Corrosion.

* Corresponding author: Address: Department of Civil and Environmental Engineering, Oklahoma State University, Stillwater, OK, 74078, USA.

Tel.: +1 405269 3280;

E-mail address: mehdi.khanzadeh_moradllo@okstate.edu (M. Khanzadeh Moradllo). 


\section{Introduction}

Concrete structures face many threats to their service life. A number of durability problems are caused by external fluids penetrating into cement-based materials [1-4]. These fluids can contain potentially harmful ionic species, can lead to damage from corrosion, sulfate attack, alkali silica reaction, bulk freeze thaw, and salt scaling [5-6]. Therefore, the ion transport properties of cement-based materials play an important role in the durability performance of concrete structures [7-8].

Concrete that is partially saturated has a more rapid and more complicated method of ion transport [9-13]. For concrete with very low relative humidity $(\mathrm{RH})$ or low degree of saturation (DoS), many pores are empty and these empty pores will draw in outside fluid from capillary action when wetted. However, more work is needed to understand how materials conditioned at different RH or different DoS impact this process.

The most widely used method to investigate fluid ingress into partially-saturated samples is through gravimetric measurements according to ASTM C 1585 and CEN EN 1925. This test method determines the one-dimensional rate of fluid penetration in cement-based materials by measuring the increase in the weight of a specimen as a function of time. However, this method only measures the total cumulative fluid uptake into the material and does not provide information about the spatial distribution of the fluid in the specimen [12,14-15]. This test makes assumptions about the geometry of the concrete pore network to estimate a depth of penetration [9-10,14]. Furthermore, this method does not account for the porosity, initial DoS of the sample, and the effect of the fluid viscosity and surface tension on penetration [11].

Recently, neutron and X-ray imaging techniques have been used to visualize fluid penetration in cement-based materials $[8,12,14-17]$. Both of these methods are based on the same 
principle of radiation attenuation when passing through matter. However, X-rays interact with the electron shell of the atom while neutrons interact with the nucleus. One drawback of neutron imaging is that it requires a high energy source that is typically only available at synchrotron beamlines. This reduces the availability of the method. Neutron imaging is also sensitive to hydrogen atoms and is not able to measure specific ions. This may or may not be important depending on the information needed.

Transmission X-ray microscopy (TXM) has been used to learn more about moisture movement in cement-based materials [7-8, 12,16,18-19]. Previous studies using this method have tried to image water penetration into the paste and mortar samples $[8,12,19]$. Unfortunately, X-rays have a weak interaction with light atoms such as hydrogen. This limits the detection sensitivity of water in the method $[8,20]$. Furthermore, experiments that use TXM to investigate water ingress cannot provide spatial information about the ions and these publications have not been validated by other experimental techniques.

In this work, the moisture penetration is imaged with the aid of using potassium iodide (KI) as a tracer. Iodine is strongly X-ray attenuating because of its high atomic number. Furthermore, iodide and chloride ions are similar in size (iodide radius is 206 pm versus a chloride radius of $167 \mathrm{pm}$ ). This property makes iodide an excellent tracer for fluid transport study in concrete [21-24]. As the tracer penetrates into the cement paste it is possible to see the corresponding changes in X-ray absorption or gray value of the material in the radiograph. These images can be captured in less than a minute. This allows time resolved images to be taken and a rate of ion penetration can be calculated. Since this technique is non-destructive, the same sample can be monitored over time or in different conditions. The method requires minimal 
sample preparation and the technique can image at a spatial resolution of $200 \mathrm{~nm}$ to $20 \mu \mathrm{m}$ with laboratory equipment.

This work aims to use TXM to investigate in-situ iodide penetration in paste samples with water-to-cement ratio (w/c) of 0.40 . These samples were conditioned in four different RHs to examine the effect of $\mathrm{DoS}$ on the ion penetration progress. The penetration of $\mathrm{Cl}$ and $\mathrm{I}$ in paste samples was also determined gravimetrically and with micro X-ray fluorescence $(\mu \mathrm{XRF})$ at these same conditions and then compared with the TXM results. $\mu$ XRF provides individual compositional maps which can be combined into a single map that simultaneously provides unique compositions and location [25-29]. Furthermore, $\mu$ XRF imaging was used to compare I and $\mathrm{Cl}$ penetration concentration profiles in paste samples.

\section{Experimental Methods}

\subsection{Mixture Proportion and Sample Preparation}

The cement is an ASTM C 150, Type I. The chemical composition of cement with bulk XRF is provided in Table 1. The paste mixture had a w/c of 0.40 and the mixture proportion is given in Table 2. Cylindrical micro vials with inside dimension of $9.5 \times 46 \mathrm{~mm}$ were used to cast the samples. A lid was used to seal each vial. The vials were partially filled up to $30 \pm 1 \mathrm{~mm}$. Twelve samples were made for each RH condition (three samples to measure KI penetration with TXM, six samples for gravimetric measurement of $\mathrm{KI}$ and $\mathrm{NaCl}$ penetration, and three samples for measuring porosity and DoS). All samples were cured for $35 \mathrm{~d}$ in a sealed condition at $23^{\circ} \mathrm{C}$ to remove the impacts of early hydration on the measurements. Based on previous publications by other researchers these samples would be expected to have a 70\% degree of hydration [3031]. 
Table 1. Chemical composition of cement with bulk XRF

\begin{tabular}{ccccccccccc}
\hline $\begin{array}{c}\text { Oxide content } \\
(\%)\end{array}$ & $\mathrm{SiO}_{2}$ & $\mathrm{Al}_{2} \mathrm{O}_{3}$ & $\mathrm{Fe}_{2} \mathrm{O}_{3}$ & $\mathrm{CaO}$ & $\mathrm{MgO}$ & $\mathrm{Na}_{2} \mathrm{O}$ & $\mathrm{K}_{2} \mathrm{O}$ & $\mathrm{TiO}_{2}$ & $\mathrm{SO}_{3}$ & L.O.I \\
\hline Type I & 20.40 & 5.03 & 2.95 & 62.89 & 2.08 & 0.35 & 0.35 & 0.28 & 3.05 & 2.09 \\
\hline
\end{tabular}

Table 2. Cement paste mixture proportion

\begin{tabular}{cccc}
\hline Mixture & water $(\mathrm{g})$ & cement $(\mathrm{g})$ & $\mathrm{w} / \mathrm{c}$ \\
\hline P-40 & 340 & 850 & 0.40 \\
\hline
\end{tabular}

After $35 \mathrm{~d}$ curing, the samples were demolded and conditioned at four different RHs $\approx \approx$ $0 \%, 35 \%, 70 \%$, and $100 \%$ ). The $35 \%$ and $70 \%$ RH samples were stored in sealed containers above saturated $\mathrm{MgCl}_{2}$ and $\mathrm{KI}$ salt solutions at $23{ }^{\circ} \mathrm{C}$ according to ASTM E 104 to reach mass equilibrium, respectively. An RH sensor was used for each container to monitor and verify the $\mathrm{RH}$. The samples were placed in the container and their mass was measured daily until there was less than $0.03 \%$ change in mass loss over a $24 \mathrm{~h}$ period. It was then assumed that the moisture in the pore networks had sufficiently equilibrated with the environment. The $35 \%$ and $70 \% \mathrm{RH}$ samples reached mass equilibrium after $50 \mathrm{~d}$ and $30 \mathrm{~d}$, respectively.

The $100 \%$ RH samples were submerged in tap water inside a sealed container. The tap water was first boiled and allowed to cool to ambient temperature according to ASTM C 1202. These samples were then measured every $24 \mathrm{~h}$ until there was less than $0.03 \%$ mass change. This was reached after $5 \mathrm{~d}$. The $\approx 0 \% \mathrm{RH}$ samples were stored in a sealed container above saturated $\mathrm{MgCl}_{2}$ solution $(35 \% \mathrm{RH})$ at $23{ }^{\circ} \mathrm{C}$ for $40 \mathrm{~d}$ and then dried in an oven at $50{ }^{\circ} \mathrm{C}$ for $7 \mathrm{~d}$ until there was no measurable change in mass. For these samples they were assumed to be at approximately $0 \%$ RH and consequently a DoS of $0 \%$. Because there may still be some moisture in the pores these samples are labeled as $\mathrm{RH} \approx 0 \%$ and $\mathrm{DoS} \approx 0 \%$. 
Since the $35 \% \mathrm{RH}$ samples required $50 \mathrm{~d}$ to reach mass equilibrium, all samples were kept in a sealed container at $23{ }^{\circ} \mathrm{C}$ until $50 \mathrm{~d}$ in order to test all samples at the same age. The mass of the samples was monitored during the storage before testing and the mass change was found to be negligible.

\subsection{Determining DoS}

The samples for porosity and DoS were left in their respective environments and the $100 \%$ RH sample was kept in a sealed container within an environmental chamber at $97 \pm 1 \% \mathrm{RH}$ at $23{ }^{\circ} \mathrm{C}$ until they were tested. The porosity and DoS of the samples were determined according to ASTM C 642. Three samples from each RH condition were submerged in water and weighed after achieving mass equilibrium. Next, the weight of the saturated samples immersed in water was measured and then the samples were dried in an oven at $50{ }^{\circ} \mathrm{C}$ and weighed again. In all measurements, it was assumed that the sample had reached mass equilibrium when the mass change was less than $0.03 \%$ during a $24 \mathrm{~h}$ period. The porosity and DoS for each sample at different RH is summarized in Table 3 .

Table 3. Porosity and DoS of paste samples at different RH

\begin{tabular}{cccc}
\hline RH & Porosity $(\%)$ & DoS $(\%)$ & $\mathrm{D}_{\mathrm{i}}(\%)^{*}$ \\
\hline$\approx 0 \%$ & $39.8 \pm 0.6$ & $0^{* *}$ & 0 \\
$35 \%$ & $42.8 \pm 0.6$ & $40.8 \pm 0.1$ & $17.5 \pm 0.3$ \\
$70 \%$ & $40.2 \pm 0.1$ & $68.8 \pm 0.5$ & $27.7 \pm 0.4$ \\
$100 \%$ & $38.5 \pm 0.2$ & 100 & $38.5 \pm 0.2$ \\
\hline${ }^{*} \mathrm{D}_{\mathrm{i}}$ is the initial DoS of the sample in volume fraction. \\
${ }^{* *}$ It has been assumed that an approximate DoS of $0 \%$ achieved in this condition.
\end{tabular}

\subsection{In-Situ Ion Penetration Using TXM}

The samples that were investigated for ion ingress were sealed with wax on all sides but the finished surface $50 \mathrm{~d}$ after curing. After sealing, the samples were placed inside a cylindrical 
plastic vial with a $25 \mathrm{~mm}$ diameter and $65 \mathrm{~mm}$ height. A hole with diameter of $10 \mathrm{~mm}$ was drilled in the lid of the vial to hold the sample. Next, water resistant epoxy was used to align the sample vertically and to seal the area between the sample and hole. A small piece of aluminum wire of $0.6 \mathrm{~mm}$ diameter was attached to the side of the vial to help align the images. The setup is shown in Fig. 1.

(a)

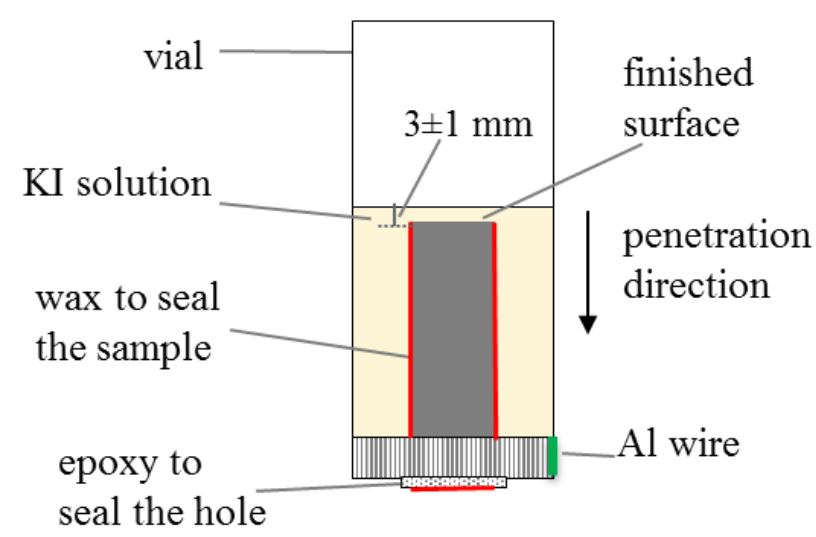

(b)

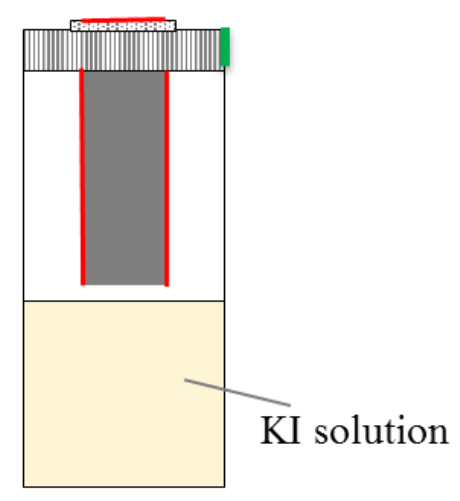

Fig. 1. Schematic diagram of the penetration test setup to measure penetration (a) and for scanning (b).

Next, the surface of the sample was ponded with $0.6 \mathrm{~mol} / \mathrm{L} \mathrm{KI}$ up to a level of $3 \pm 1 \mathrm{~mm}$ for $14 \mathrm{~d}$. This KI concentration was selected based on preliminary experiments to attain suitable contrast between the KI solution and the paste. As shown in Fig. 1a, the samples were stored where the fluid penetration and gravity effects are in the same direction. This simulates fluid penetration in flat surfaces such as bridge decks, an important application for the findings of this work. The KI solution level above the surface of samples was kept constant for all paste samples $(3 \pm 1 \mathrm{~mm})$. The KI solution was refreshed every $5 \mathrm{~d}$ to maintain a constant KI concentration. Samples were stored inside a sealed container at $23^{\circ} \mathrm{C}$ during the penetration testing. 
A laboratory Skyscan $1172 \mu \mathrm{CT}$ was used to conduct the experiments. A radiograph was taken from the paste samples before ponding with KI solution. This was used as a reference radiograph. Radiographs were also taken over time to track the fluid penetration into the sample. The time intervals for taking radiographs were selected according to ASTM C 1585 recommendations for gravimetric measurements. This allowed a comparison to be made between the moisture penetration into the sample and the mass change. The vial was inverted to stop the fluid penetration during the imaging as shown in Fig. 1b. Each radiograph took less than 1 min and so this should not disturb the test. Radiographs were also taken with no samples on the stage to be used to subtract the background attenuation. This also helped correct for variations in X-ray transmission between images. The radiograph used a pixel size of $8.8 \mu \mathrm{m}$ (2096×2096 pixels) and tube voltage and current of $100 \mathrm{KeV}$ and $100 \mu \mathrm{A}$. A $0.5 \mathrm{~mm} \mathrm{Al}$ and 0.5 $\mathrm{mm} \mathrm{Cu}$ filter was used to absorb lower energy X-rays and allow high energy X-rays to interact with the sample. Acquisition time of $8 \mathrm{~s}$ per frame was used to collect each radiograph. Table 4 summarizes the TXM settings.

\section{4 $\mathrm{Cl}$ and I Penetration Test Using the Gravimetric Method}

The same experimental setup as TXM was used to gravimetrically measure ion penetration in paste samples, but instead of radiographs, the mass of the sample was measured. The paste samples were ponded with either $0.6 \mathrm{~mol} / \mathrm{L} \mathrm{KI}$ or $0.6 \mathrm{~mol} / \mathrm{L} \mathrm{NaCl}$ solutions for $14 \mathrm{~d}$ to compare I and $\mathrm{Cl}$ ion penetration. Three samples were tested for each salt solution. The sample was taken out of the vial for the weight measurement and excess solution at the surface and sides of the sample was removed with a damp paper towel before weighing. An empty vial was used on the scale to place the sample and avoid the contact between wet surface of the sample and scale pan. The sample was immediately returned back to solution after measurement. A scale 
with $0.002 \%$ accuracy was used for the gravimetric measurements. The sample was polished and then analyzed with $\mu \mathrm{XRF}$ after the ponding period to compare the results.

\subsection{Comparing $\mathrm{Cl}$ and I Penetration Using $\mu \mathrm{XRF}$}

As explained earlier, the paste samples were ponded with either $0.6 \mathrm{~mol} / \mathrm{L} \mathrm{KI}$ or 0.6 $\mathrm{mol} / \mathrm{L} \mathrm{NaCl}$ solutions for $14 \mathrm{~d}$ to compare I and $\mathrm{Cl}$ penetration rate. After the ponding period, the investigated samples from TXM and mass change were polished for analysis with $\mu \mathrm{XRF}$ to compare the results. Each sample was polished on a sanding belt for 2 min with 120 grit sandpaper to create a flat surface for further analysis with $\mu$ XRF. Ethanol was used to remove dirt and residue from the polished surface.

The $\mu \mathrm{XRF}$ analysis was conducted using the Orbis by EDAX. The instrument uses an 80 $\mathrm{mm}^{2}$ Silicon Drift Detector Energy Dispersive Spectrometer (SDD-EDS) and a capillary optic that produces a $50 \mu \mathrm{m}$ diameter beam. Images are created by moving the sample under the stationary X-ray beam. The X-ray beam causes characteristic fluorescence X-rays to be emitted at each spot. Table 4 summarizes the settings used by the $\mu$ XRF in this work. More details can be found in other publications [25-26].

Table 4. Summary of TXM and $\mu$ XRF settings used

\begin{tabular}{lcc}
\hline Parameter & TXM & $\mu$ XRF \\
\hline voltage $(\mathrm{keV})$ & 100 & 40 \\
\hline current $(\mu \mathrm{A})$ & 100 & 1000 \\
\hline filter & $0.5 \mathrm{~mm} \mathrm{Al}+$ & $25 \mu \mathrm{m} \mathrm{Al}$ \\
& $0.5 \mathrm{~mm} \mathrm{Cu}$ & \\
\hline pixel size $(\mu \mathrm{m})$ & 8.8 & 50 \\
\hline acquisition time & $8 \mathrm{~s}$ & $400 \mathrm{~ms} /$ pixel (dwell \\
& & time) \\
\hline chamber condition & air & vacuum \\
\hline dead time & - & maximum of $20 \%$ \\
\hline
\end{tabular}

2.6 TXM Data Analysis 
First, the radiographs of the air were subtracted from sample scans to remove the background attenuation effects. Next, an average gray value profile was calculated through the sample depth. Ten scan lines were randomly used that were perpendicular to the surface of the sample. Each line was located at the middle $40 \%$ (4 $\mathrm{mm})$ of the sample to avoid beam hardening and to keep the analyzed region at an almost constant depth. The effect of inconsistent thickness of cylindrical sample on TXM results was investigated in previous publications [32] and it was not found to be significant in this region of the sample. Next, each time series radiograph was subtracted from the radiograph before solution was added to the sample. This allowed the change in the gray value to be easily observed and the spatial changes due to absorption from I to be mapped. The Beer-Lambert Law (Eq. 1) [22-23] was used to calculate a change in attenuation due to I $(\Delta \mu)$ at different depths of sample.

$(\Delta \mu)_{\mathrm{x}}=\ln \left(\mathrm{I}_{\mathrm{ref}}\right)_{\mathrm{x}}-\ln \left(\mathrm{I}_{\mathrm{t}}\right)_{\mathrm{x}}$

Where $\left(\mathrm{I}_{\mathrm{ref}}\right)_{\mathrm{x}}$ is the transmitted X-ray intensity (gray value) at depth $\mathrm{x}$ on the reference profile and $\left(\mathrm{I}_{\mathrm{t}}\right)_{\mathrm{x}}$ is the transmitted X-ray intensity at the same location at a future time. The fluid accessible porosity and the sample thickness are not included in Eq. (1) since these parameters are constant for each sample. More details can be found in other publications [32-33].

Next, standards of cement paste containing different KI concentrations were used to develop a relationship between the gray value and I concentration level. The same sample size, mixtures, curing procedure, and scan setup were used to prepare and investigate these samples. The same samples were then polished and analyzed with $\mu \mathrm{XRF}$. This again allowed the concentration and counts measurements by $\mu \mathrm{XRF}$ to be calibrated. In addition, a set of paste samples with different $\mathrm{NaCl}$ concentrations were also used to convert $\mathrm{Cl}$ counts from $\mu \mathrm{XRF}$ to 
concentrations. The calibration curves are included in the supplementary section (Figs S1 and S2).

\section{7 $\mu$ XRF Data Analysis}

A Matlab code was used to analyze the spatial and compositional data. A border detection algorithm was then used to find the top surface of the sample. The sample is then separated into $0.50 \mathrm{~mm}$ layers of equal thickness from the surface of the sample through the entire depth. The average $\mathrm{I}$ and $\mathrm{Cl}$ counts in each layer can then be plotted for different depths. Next, the calibration curves are used to convert $\mathrm{I}$ and $\mathrm{Cl}$ counts to concentrations. Additional details can be found in previous publications [25-26].

\subsection{Gravimetric Data Analysis}

According to ASTM C 1585, the penetration is the change in mass divided by the product of the exposed area of the sample and density of water, as formulated in Eq. (2).

$\mathrm{I}=\frac{\Delta \mathrm{m}}{\mathrm{A} \times \rho_{\mathrm{w}}}$

where I is the penetration; $\Delta \mathrm{m}$ is the change in sample mass; $\mathrm{A}$ is the exposed area of the sample; and $\rho_{\mathrm{w}}$ is the density of water.

However, this equation does not account for the porosity and initial DoS of the sample. In addition, it does not consider the effect of fluid viscosity and surface tension on penetration. Therefore, this equation is not directly applicable to salt solutions [11,34]. Farnam et al. [34] proposed a modified equation (Eq. (3)) to estimate the intrinsic penetration of the sample exposed to salt solution. 
$\mathrm{I}_{i}=\frac{\Delta \mathrm{m}}{\mathrm{A} \times \rho_{\mathrm{s}} \times \Phi\left(1-D_{i}\right)} \times \sqrt{\frac{\gamma_{w} \times \eta_{s}}{\gamma_{s} \times \eta_{w}}}$

where $I_{i}$ is the intrinsic penetration (this value is frequently interpreted as the depth of fluid penetration in the sample); $\rho_{\mathrm{s}}$ is the density of solution; $\Phi$ denotes the porosity of the sample in volume fraction; $\mathrm{D}_{\mathrm{i}}$ is the initial degree of saturation of the sample in volume (See Table 3); $\gamma_{\mathrm{w}}$ and $\gamma_{\mathrm{s}}$ are the surface tensions of water and solution, respectively; and $\eta_{\mathrm{w}}$ and $\eta_{\mathrm{s}}$ represent the viscosity of water and solution, respectively. In the current study, Eq. (3) was used to find the depth of fluid penetration based on the gravimetric measurements and compare to the TXM measurements. The density, viscosity, and surface tension for water and $\mathrm{NaCl}$ was obtained from [35-36], and KI from [37]. These values are summarized in Table 5.

In addition, a linear model was used to find the intrinsic penetration versus square root of time with Eq. (4) to determine the sorptivity of the samples [9,38]. For the regression analysis, all data points from $1 \mathrm{~min}$ to $6 \mathrm{~h}$ were used.

$\mathrm{I}_{i}=\mathrm{S} \times \sqrt{t}+\mathrm{B}$

where $\mathrm{S}$ is the sorptivity coefficient; $\mathrm{t}$ denotes the time; and $\mathrm{B}$ is a correction term added to account for surface effects when the sample comes in contact with the solution.

Table 5. Density, viscosity, and surface tension of solutions [35-37]

\begin{tabular}{cccc}
\hline Solution & density $\left(\mathrm{g} / \mathrm{cm}^{3}\right)$ & $\begin{array}{c}\text { viscosity } \\
(\mu \mathrm{Pa} . \mathrm{s})\end{array}$ & $\begin{array}{c}\text { surface tension } \\
\times 10^{-6}(\mathrm{~N} / \mathrm{mm})\end{array}$ \\
\hline $\mathrm{KI}$ & 1.070 & 949.48 & 73.5 \\
$\mathrm{NaCl}$ & 1.023 & 945.74 & 72.8 \\
Water & 0.997 & 890.30 & 71.8 \\
\hline
\end{tabular}

2.9 Determining I and $\mathrm{Cl}$ Penetration Coefficient 
Fick's second law for diffusion is shown in Eq. (5) [39-40],

$\frac{\partial \mathrm{C}}{\partial \mathrm{t}}=\mathrm{D}_{\mathrm{c}}\left(\frac{\partial^{2} C}{\partial x^{2}}\right)$

where $\mathrm{x}$ is distance from sample surface; $t$ denotes time; $\mathrm{D}_{\mathrm{c}}$ is diffusion coefficient; $\mathrm{C}_{\mathrm{s}}$ is surface ion concentration; and $\mathrm{C}_{(\mathrm{x}, \mathrm{t})}$ represents ion concentration at the depth of $\mathrm{x}$ from the surface after time t.

A general solution to the equation is given in Eq. (6),

$$
\begin{aligned}
& C_{(x, t)}=C_{s}\left(1-\operatorname{erf}\left(\frac{x}{2 \sqrt{D_{c} \times t}}\right)\right) \\
& C_{(x, 0)}=0 \quad x>0, \quad C_{(0, t)}=C_{s} \quad t \geq 0
\end{aligned}
$$

where $\mathrm{x}$ is distance from sample surface; $\mathrm{t}$ denotes time; $\mathrm{C}_{\mathrm{s}}$ is surface ion concentration; $\mathrm{C}_{(\mathrm{x}, \mathrm{t})}$ represents ion concentration at the depth of $\mathrm{x}$ from the surface after time $\mathrm{t}$; and erf is the error function and $D_{c}$ is the diffusion coefficient in a fully saturated sample.

Both Eq. (5) and (6) assume that the porous material is fully saturated; the ion concentration at the exposure surface is constant; and there is no impact of co-existing ions. In addition, this equation does not take into account the effect of other ion penetration mechanisms such as capillary absorption. Although these assumptions do not apply to all of the conditions in this study, this equation may still be useful where diffusion plays a significant role in the penetration of outside ions and so these models will be used for comparative purposes.

In the case of $\approx 0 \%, 35 \%, 70 \%, 100 \% \mathrm{RH}$ samples, a nonlinear regression was conducted on I and $\mathrm{Cl}$ profiles from TXM and $\mu \mathrm{XRF}$ with a modified version of Eq. (6) that is shown in Eq. (7). First, the diffusion coefficient $\left(D_{c}\right)$ was replaced with a term called the penetration 
coefficient $\left(\mathrm{P}_{\mathrm{c}}\right)$. This term primarily controls the slope of the line describing the concentration versus depth into the sample. This term has been renamed because the penetration of the outside ions is controlled by a combination of mechanisms and not just diffusion. Next, a constant value, known as the absorption coefficient $\left(\mathrm{A}_{\mathrm{c}}\right)$, was added that can account for the initial uptake or absorption of the fluid into the samples. The absorption coefficient was zero for all samples except for the $\approx 0 \% \mathrm{RH}$ sample. Because the $\approx 0 \% \mathrm{RH}$ samples required a combination of both the absorption coefficient (a constant value) and the penetration coefficient (value that controls the slope) the $\mathrm{P}_{\mathrm{c}}$ for the $\approx 0 \% \mathrm{RH}$ sample is not able to be compared with the $\mathrm{P}_{\mathrm{c}}$ of the other samples. This is likely caused by the vastly different mode of ion transport in this sample. This will be an area of future research.

$\mathrm{C}_{(\mathrm{x}, \mathrm{t})}=\mathrm{C}_{\mathrm{s}}\left(1-\operatorname{erf}\left(\frac{\mathrm{x}}{2 \sqrt{\mathrm{P}_{\mathrm{c}} \mathrm{t}}}\right)\right)+\mathrm{A}_{c}$

\section{Results and Discussion}

\subsection{Comparison of TXM Results with $\mu$ XRF}

Figure 2 shows a comparison between concentration profiles from $\mu \mathrm{XRF}$ and TXM for paste samples with different DoS after $14 \mathrm{~d}$ of ponding with $0.6 \mathrm{M} \mathrm{KI}$ solution. In addition, the calculated $\mathrm{P}_{\mathrm{c}}$ for I and percent difference from both methods based on Eq. (7) are summarized in Table 6. Based on Fig. 2, the two techniques show a good correlation. The difference between the $\mathrm{P}_{\mathrm{c}}$ for I from TXM and $\mu \mathrm{XRF}$ was on average $4 \%$ for paste samples conditioned in different RHs. This shows that there is good agreement between $\mu \mathrm{XRF}$ and TXM for the investigated samples and conditions. In addition, a two tail t-test with the assumption of unequal variances was conducted to compare the mean $\mathrm{P}_{\mathrm{c}}$ of the two methods. Based on this analysis, the 
difference between means was not significant $(p$-value $=0.93>0.05)$. This suggests that these two methods provide statistically comparable results. Therefore, this suggests that TXM method based on the established procedure and spatial resolution provides reliable results for ion penetration in cement-based materials for these time scales and materials.
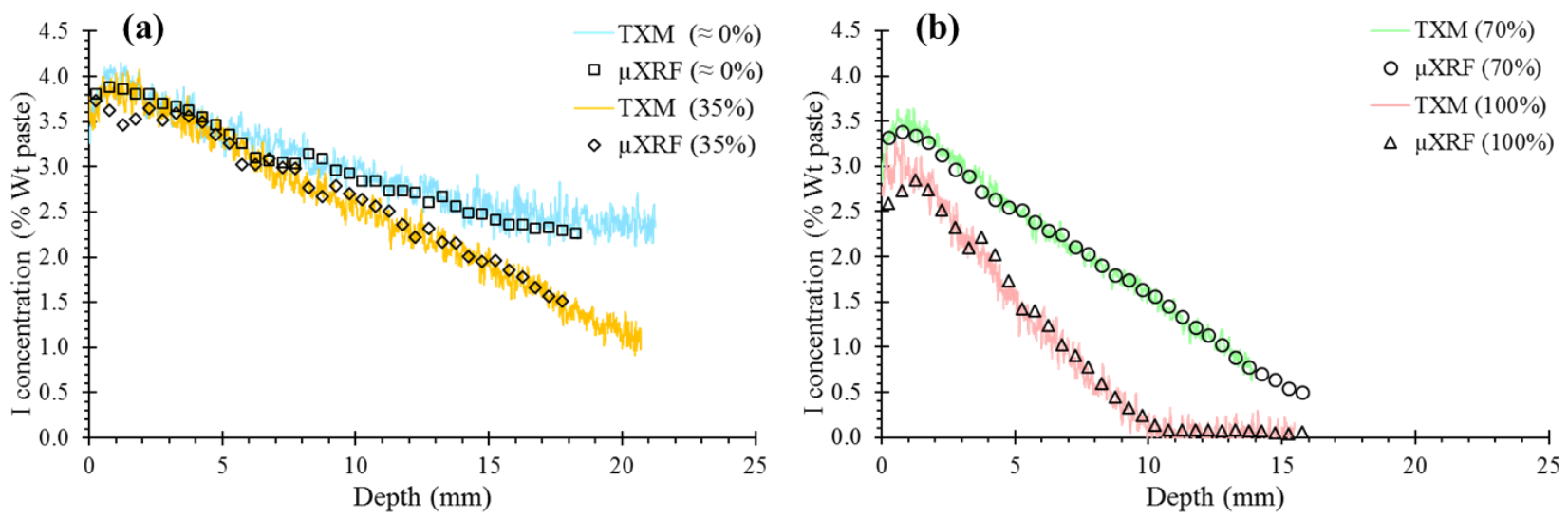

Fig. 2. Comparison of TXM results (lines) with results from $\mu$ XRF (data points) for paste samples with w/c of 0.40 conditioned in: (a) $\approx 0 \%$ and $35 \%$ RHs (b) $70 \%$ and $100 \%$ RHs.

Table 6. Comparison between I penetration coefficients from TXM and $\mu \mathrm{XRF}$

\begin{tabular}{cccccc}
\hline Sample & $\begin{array}{c}\text { TXM } \\
\text { Pen Coef } \times 10^{-11} \\
\left(\mathrm{~m}^{2} / \mathrm{sec}\right)\end{array}$ & $\mathrm{R}^{2}$ & $\begin{array}{c}\mu \text { XRF } \\
\text { Pen Coef } \times 10^{-11} \\
\left(\mathrm{~m}^{2} / \mathrm{sec}\right)\end{array}$ & $\mathrm{R}^{2}$ & $\frac{\begin{array}{c}\% \text { Difference } \\
(\mathrm{TXM}-\mu \mathrm{XRF})\end{array}}{\mu \mathrm{XRF} \times 0.01}$ \\
\hline$\approx 0 \%$ & 6.62 & 0.95 & 6.56 & 0.99 & 0.9 \\
$35 \%$ & 16.13 & 0.98 & 17.92 & 0.99 & -10 \\
$70 \%$ & 5.86 & 0.99 & 5.89 & 0.99 & -0.5 \\
$100 \%$ & 1.41 & 0.98 & 1.47 & 0.98 & -4 \\
\hline
\end{tabular}

\subsection{Comparison of the I and $\mathrm{Cl}$ Penetration}

Figure 3 shows a comparison between $\mathrm{KI}$ and $\mathrm{NaCl}$ intrinsic penetration by gravimetric measurements for samples conditioned at different $\mathrm{RH}$ and ponded with $0.6 \mathrm{M} \mathrm{KI}$ and $0.6 \mathrm{M}$ $\mathrm{NaCl}$ solutions for $14 \mathrm{~d}$. In addition, the calculated sorptivity coefficients from the initial penetration versus square root of time by using Eq. (4) are summarized in Table 7. Based on 
Fig. 3, there is a similar penetration for both the $\mathrm{KI}$ and $\mathrm{NaCl}$ samples with matching DoS. The average difference between the calculated $\mathrm{KI}$ and $\mathrm{NaCl}$ sorptivity coefficients of different samples is about $15 \%$. KI showed higher sorptivity in samples with lower DoS compared to $\mathrm{NaCl}$. However, the initial penetration of $\mathrm{KI}$ is lower than $\mathrm{NaCl}$ in the case of paste samples with higher DoS (e.g. $70 \%$ and 100\% RH samples). This can be attributed to the differences in fluid properties such as surface tension.

In addition, the $\mathrm{I}$ and $\mathrm{Cl}$ concentration profiles of samples from $\mu \mathrm{XRF}$ after $14 \mathrm{~d}$ ponding with 0.6 M KI and 0.6 M NaCl solutions are shown in Fig. 4. The calculated I and $\mathrm{Cl}$ penetration coefficients from concentration profiles by using Eq. (7) are summarized in Table 8. The average difference between the calculated $\mathrm{I}$ and $\mathrm{Cl}$ penetration coefficients of different samples is about $6 \%$. Because of the differences in fluid properties, size and ionic mobility we would not expect the penetration rate to be the same for these two different ions. Overall, I shows a similar penetration performance to $\mathrm{Cl}$ in paste samples with different DoS and serves as a satisfactory substitute to understand ion penetration.

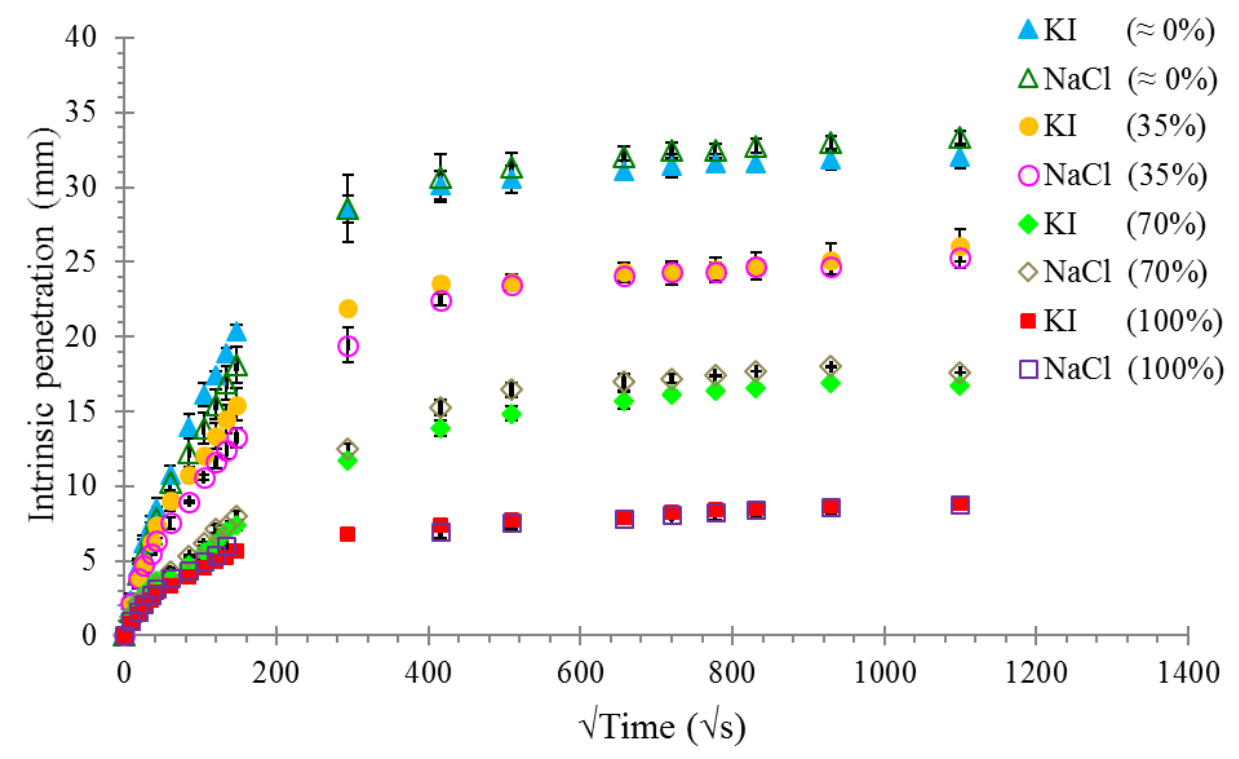


Fig. 3. Time-dependent $\mathrm{KI}$ and $\mathrm{NaCl}$ intrinsic penetration in paste samples with w/c of 0.40 conditioned in different RHs by gravimetric method.

Table 7. Comparison between $\mathrm{KI}$ and $\mathrm{NaCl}$ sorptivity coefficients from gravimetric method

\begin{tabular}{|c|c|c|c|c|}
\hline RH & parameter & $\mathrm{KI}$ & $\mathrm{NaCl}$ & $\begin{array}{c}\text { \% difference } \\
(\mathrm{KI}-\mathrm{NaCl}) \\
/ \mathrm{NaCl} \times 0.01\end{array}$ \\
\hline \multirow{3}{*}{$\approx 0 \%$} & $\mathrm{~S}(\mathrm{~mm} / \sqrt{\mathrm{s}})$ & 0.123 & 0.1096 & 12.23 \\
\hline & $\mathrm{B}(\mathrm{mm})$ & 2.835 & 2.501 & 13.35 \\
\hline & $\mathrm{R}^{2}$ & 0.99 & 0.98 & \\
\hline \multirow{3}{*}{$35 \%$} & $\mathrm{~S}(\mathrm{~mm} / \sqrt{\mathrm{s}})$ & 0.0902 & 0.0742 & 21.56 \\
\hline & $\mathrm{B}(\mathrm{mm})$ & 2.686 & 2.66 & 0.98 \\
\hline & $\mathrm{R}^{2}$ & 0.98 & 0.99 & \\
\hline \multirow{3}{*}{$70 \%$} & $\mathrm{~S}(\mathrm{~mm} / \sqrt{\mathrm{s}})$ & 0.0392 & 0.0469 & -16.42 \\
\hline & $\mathrm{B}(\mathrm{mm})$ & 1.593 & 1.256 & 26.83 \\
\hline & $\mathrm{R}^{2}$ & 0.99 & 0.99 & \\
\hline \multirow{3}{*}{$100 \%$} & $\mathrm{~S}\left(\mathrm{~mm} / ل_{\mathrm{s}}\right)$ & 0.0325 & 0.0369 & -11.92 \\
\hline & $\mathrm{B}(\mathrm{mm})$ & 1.129 & 1.227 & -7.99 \\
\hline & $\mathrm{R}^{2}$ & 0.97 & 0.97 & \\
\hline
\end{tabular}



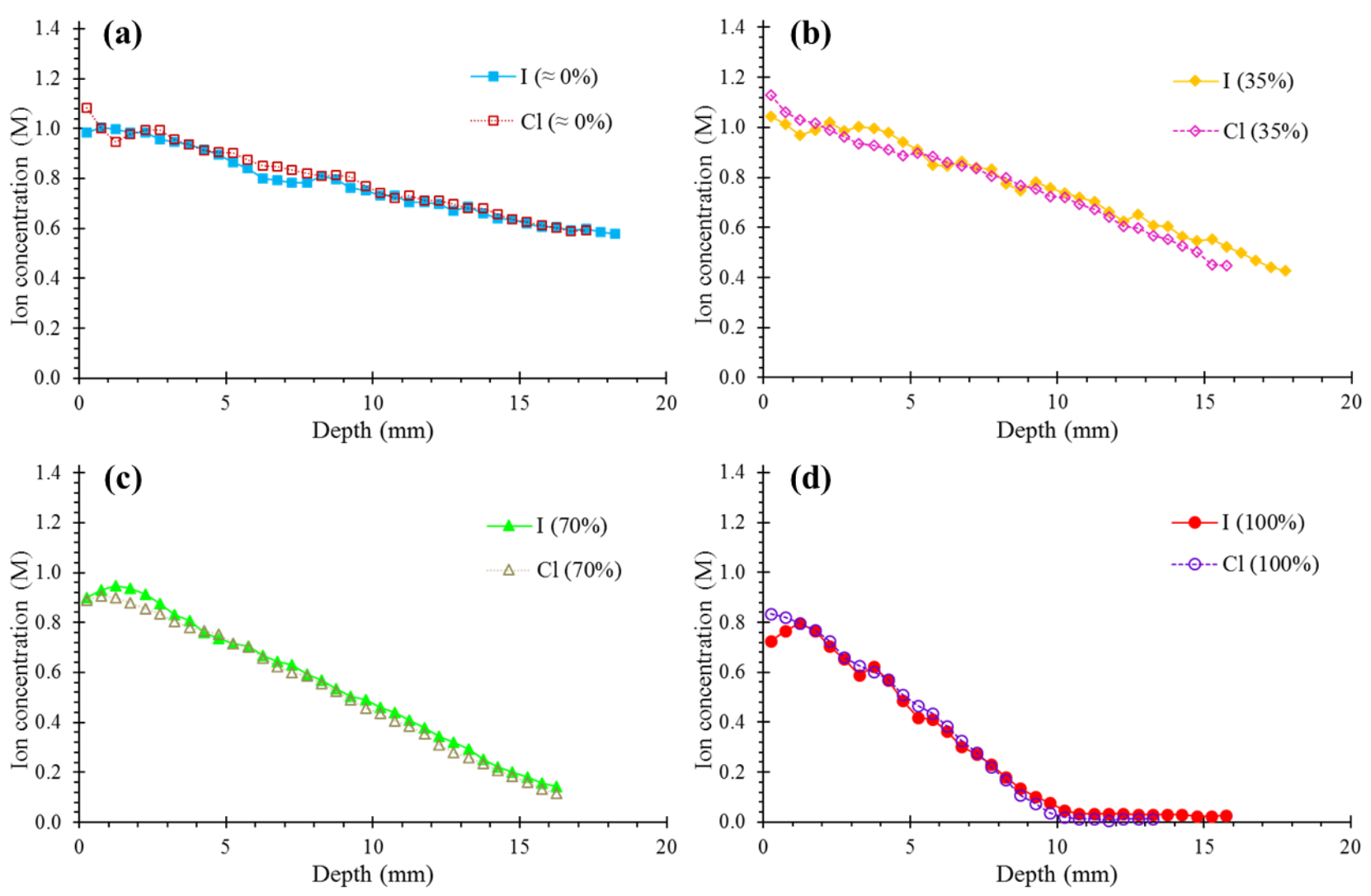

Fig. 4. Comparison of I and $\mathrm{Cl}$ concentration profiles in paste samples with w/c of 0.40 conditioned in: (a) $\approx 0 \% \mathrm{RH}$ (b) $35 \% \mathrm{RH}$ (c) $70 \% \mathrm{RH}$ (d) $100 \% \mathrm{RH}$ from $\mu \mathrm{XRF}$ after $14 \mathrm{~d}$ of ponding with $0.6 \mathrm{M}$ solution.

Table 8. Comparison between I and $\mathrm{Cl}$ penetration coefficients from $\mu \mathrm{XRF}$ after $14 \mathrm{~d}$ of ponding with $0.6 \mathrm{M}$ solution.

\begin{tabular}{lccccc}
\hline Sample & $\begin{array}{c}\mathrm{I} \\
\text { Pen Coef } \times 10^{-11} \\
\left(\mathrm{~m}^{2} / \mathrm{sec}\right)\end{array}$ & $\mathrm{R}^{2}$ & $\begin{array}{c}\mathrm{Cl} \\
\mathrm{Pen} \mathrm{Coef} \times 10^{-11} \\
\left(\mathrm{~m}^{2} / \mathrm{sec}\right)\end{array}$ & $\mathrm{R}^{2}$ & $\frac{\text { \% Difference }}{(\mathrm{I}-\mathrm{Cl})}$ \\
\hline$\approx 0 \%$ & 6.56 & 0.99 & 7.72 & 0.99 & -15 \\
$35 \%$ & 17.92 & 0.99 & 17.76 & 0.98 & 0.9 \\
$70 \%$ & 5.89 & 0.99 & 6.13 & 0.98 & -3.9 \\
$100 \%$ & 1.47 & 0.98 & 1.55 & 0.97 & -5 \\
\hline
\end{tabular}

3.3 Time Resolved I Penetration with TXM 
Figs 5 to 13 compare the I penetration and concentration profiles of the paste samples after $5 \mathrm{~min}, 30 \mathrm{~min}, 1 \mathrm{~h}, 2 \mathrm{~h}, 6 \mathrm{~h}, 1 \mathrm{~d}, 5 \mathrm{~d}, 8 \mathrm{~d}$ and $14 \mathrm{~d}$ of ponding with the KI solution. The depth of penetration was estimated by reporting where the I concentration was greater than 0.10 $\%$ weight of the paste $(\approx 0.14 \%$ weight of the cement $)$. This value was chosen so that it was statistically greater than background I concentration found at inner depths of the samples where the solution had not penetrated. This data shows that TXM is capable of providing time-series penetration depths and concentration profiles with high spatial resolution. Because of the high resolution of the data, the I profile can be measured within minutes of adding the material to the surface.

Based on Figs 5 to 13, all paste samples showed initial absorption within $2 \mathrm{~mm}$ to $4 \mathrm{~mm}$ of the surface after 5 min of ponding. However, the rate of I penetration in samples with lower $\operatorname{DoS}(\approx 0 \%$ and $35 \% \mathrm{RH})$ is much higher than samples with higher DoS with time. The $\approx 0 \%$ and $35 \%$ RH samples showed 3.5x more penetration than the $100 \% \mathrm{RH}$ samples after $1 \mathrm{~h}$ of ponding. The I penetrated for the $\approx 0 \%$ and $35 \% \mathrm{RH}$ samples was observed over the entire scan depth $(\approx 20 \mathrm{~mm})$ after only $6 \mathrm{~h}$ of ponding. After $14 \mathrm{~d}$ of ponding the I penetration of the $100 \%$ $\mathrm{RH}$ sample reached $\approx 11.5 \mathrm{~mm}$. This highlights the change in ion transport with different saturation levels. The low DoS samples will have a higher number of empty pores. These empty pores will create greater capillary forces that draw the fluid into the sample. Modeling efforts are underway and will be presented in future publications.

In addition, the non-destructive nature of TXM enables us to visualize and quantify the combined transport mechanisms at early ages. Based on Figs 5 to 13, the concentration profiles can be categorized into three different types of transport: diffusion-based profiles (e.g. profiles of $100 \%$ RH sample); absorption-based profiles (e.g. profiles of $\approx 0 \% \mathrm{RH}$ samples at early ages; 
Fig. 5); and profiles from combined transport mechanisms (e.g. profiles of 35\% RH and 75\% RH samples).

Figure 14 provides an overview of the ion penetration for the $\approx 0 \% \mathrm{RH}$ sample. There is a constant I concentration following the ion penetration front. The initial ion penetration is likely caused by capillary absorption. This occurs at the onset of ion penetration into the sample and is described by a front progressing through the sample. Following this region the concentration profile seems to change so that there are two modes of ion penetration. It is interesting that the $\approx 0 \% \mathrm{RH}$ and the $35 \% \mathrm{RH}$ samples have almost the same ion concentration from the sample surface until $4 \mathrm{~mm}$ from the surface for all of the time periods investigated. This can be due to higher capillary forces at the surface of these samples resulting from the lower DoS.

The $35 \% \mathrm{RH}$ and $70 \% \mathrm{RH}$ samples show an almost linear slope over the depth of penetration. This shape is different from pure ionic diffusion and could be caused by a mixed mode of ion transport from diffusion and capillary absorption. The $100 \%$ RH sample shows a more typical diffusion shaped curve. A comparison between the calculated $\mathrm{P}_{\mathrm{c}}$ of samples with different DoS will be discussed later in the paper. 


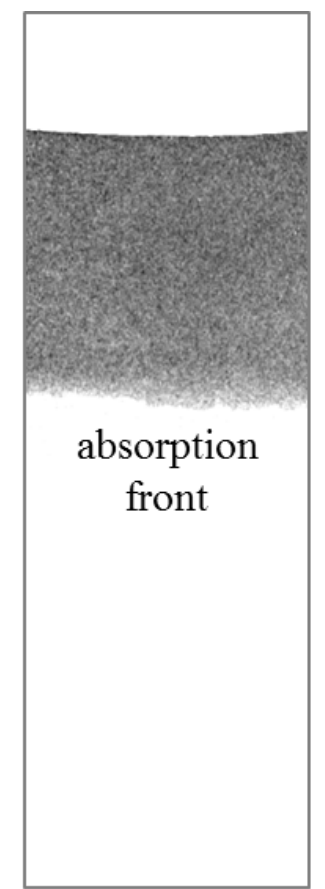

$\approx 0 \% \mathrm{RH}$

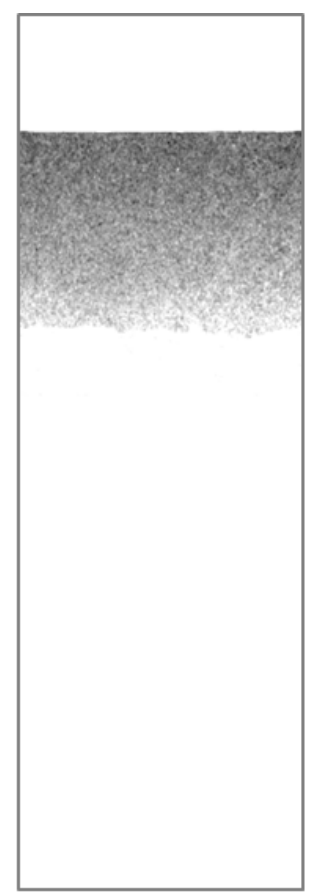

$35 \% \mathrm{RH}$

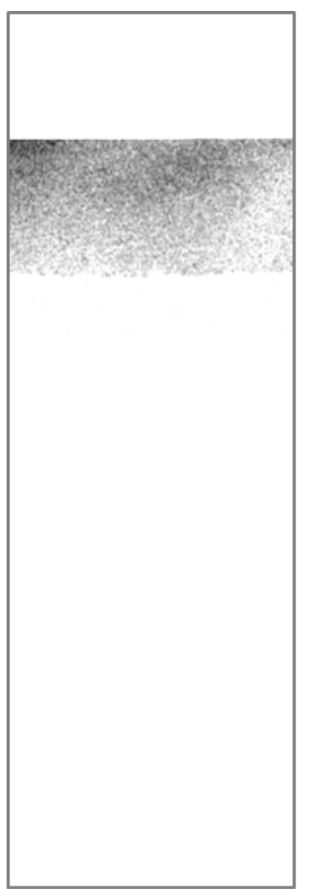

$70 \% \mathrm{RH}$

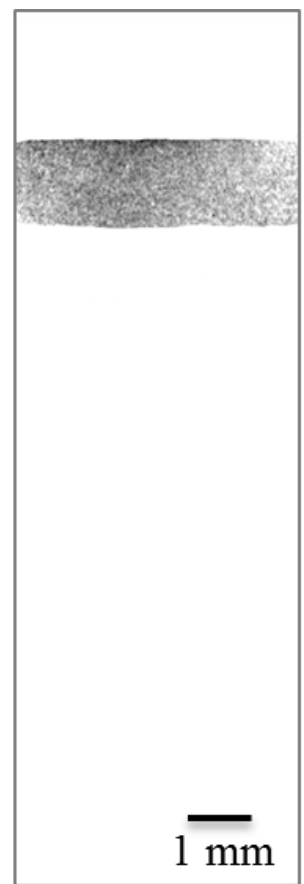

$100 \% \mathrm{RH}$

I penetration depth $(\mathrm{mm})$

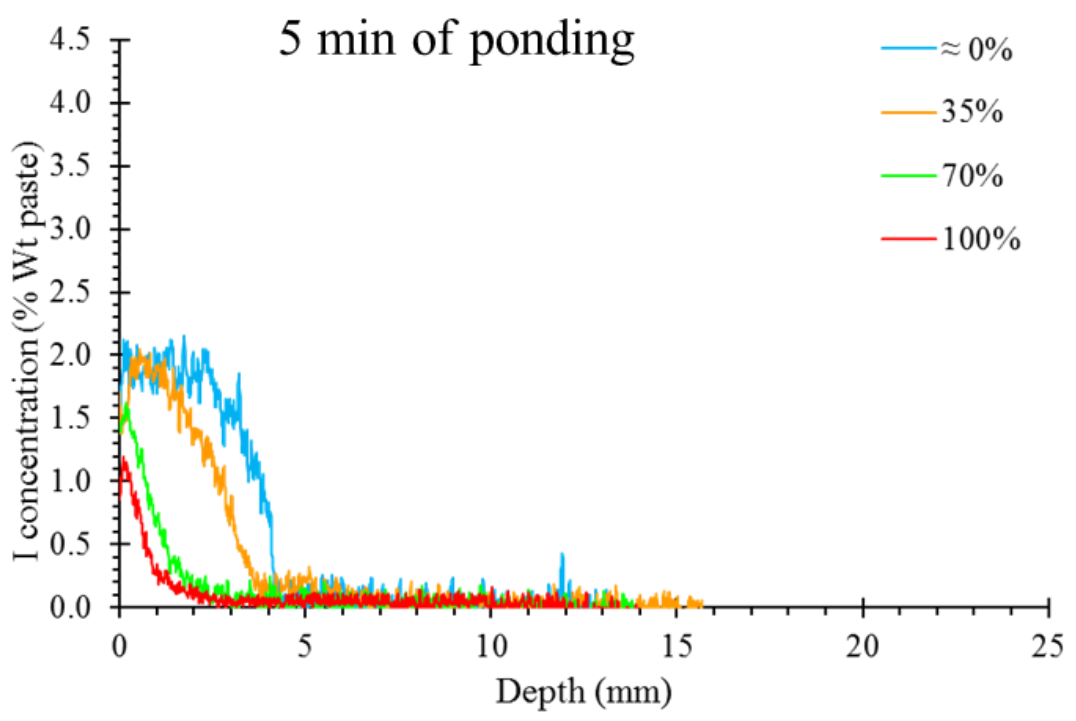

Fig. 5. TXM comparison of I penetration in different $\mathrm{RH}$ after 5 min ponding. 


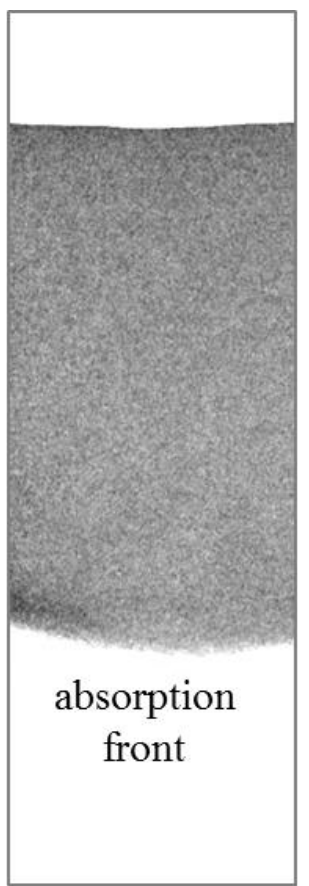

$\approx 0 \% \mathrm{RH}$

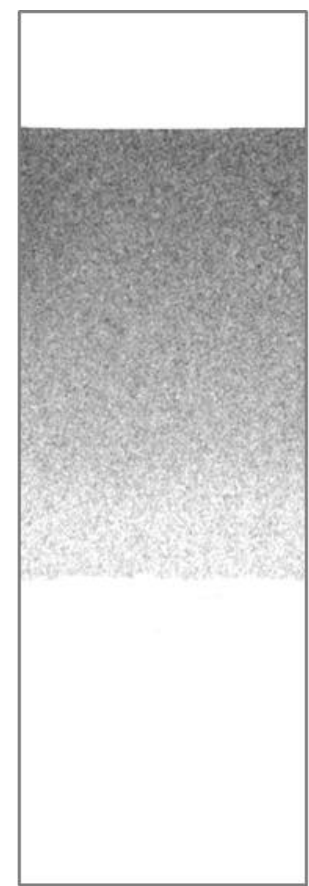

$35 \% \mathrm{RH}$

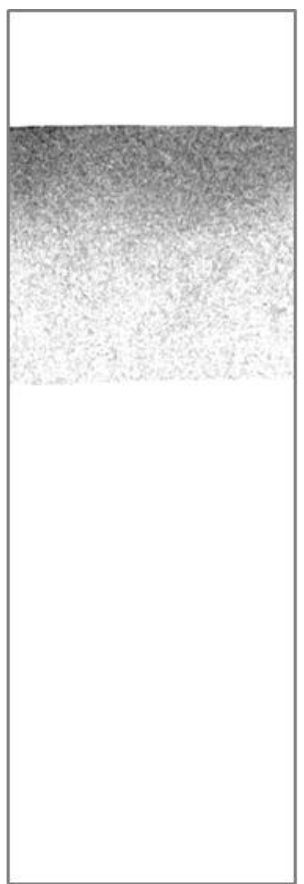

$70 \% \mathrm{RH}$

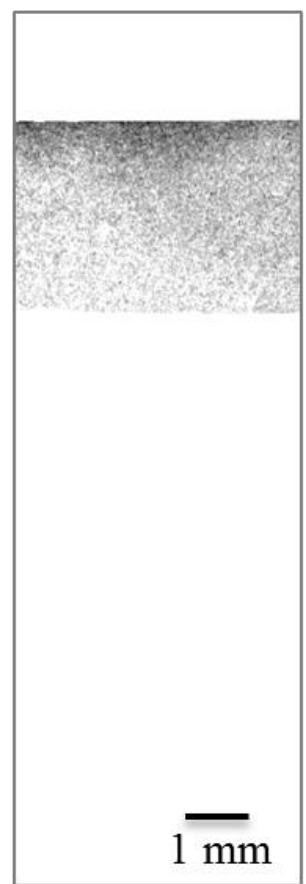

$100 \% \mathrm{RH}$

I penetration depth $(\mathrm{mm})$

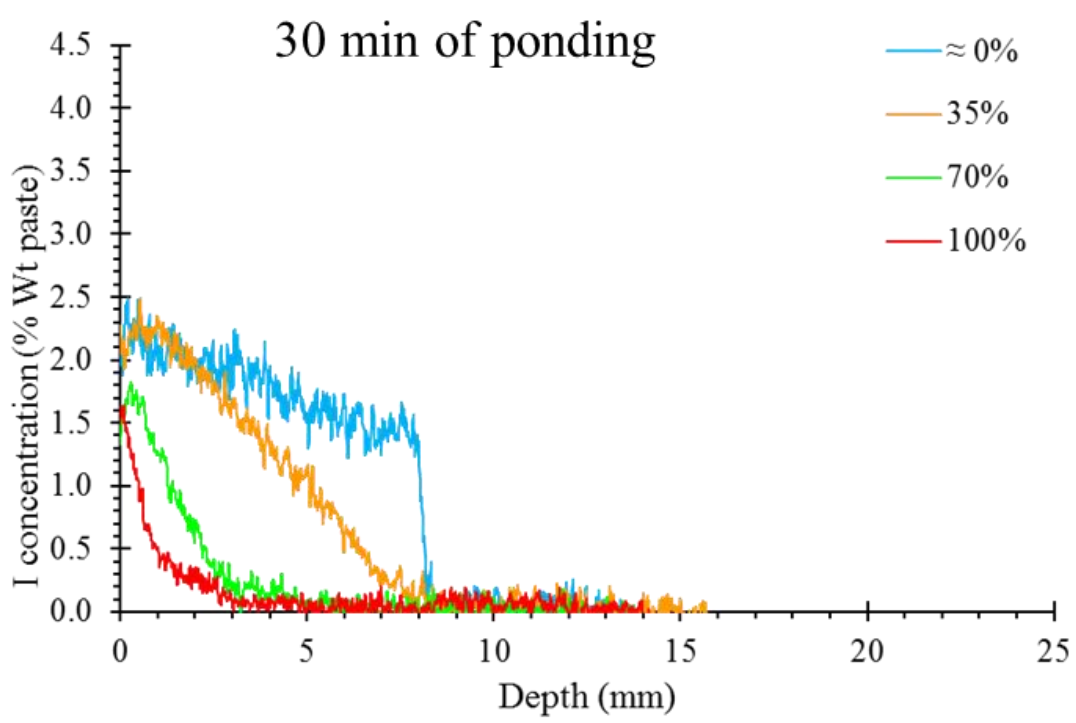

Fig. 6. TXM comparison of I penetration in different RH after $30 \mathrm{~min}$ ponding. 


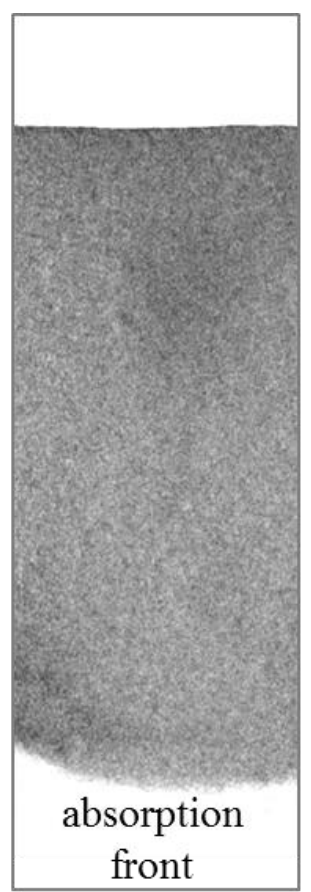

$\approx 0 \% \mathrm{RH}$

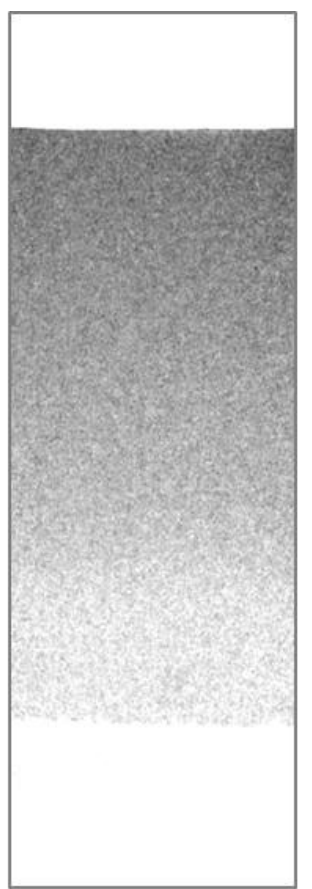

$35 \% \mathrm{RH}$

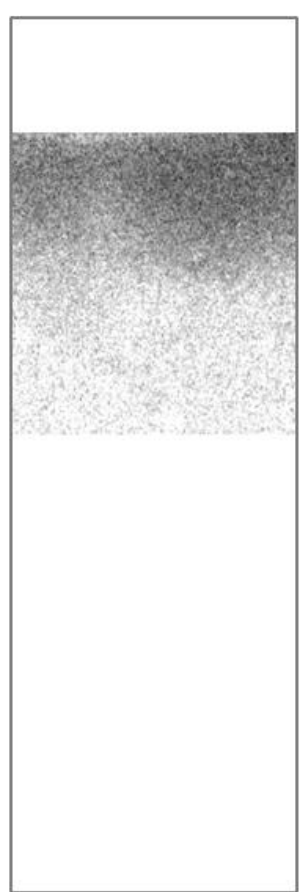

$70 \% \mathrm{RH}$

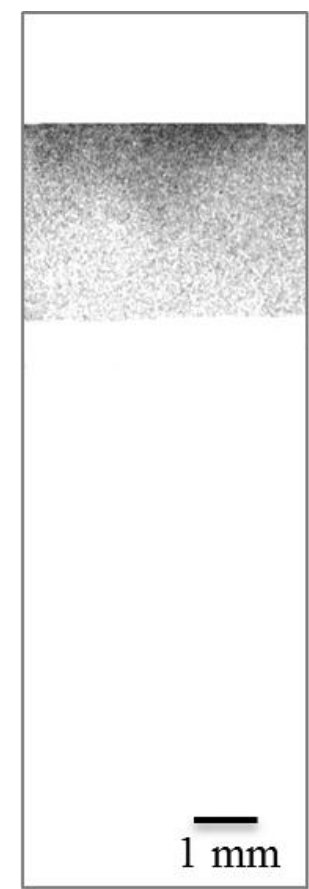

$100 \% \mathrm{RH}$

I penetration depth $(\mathrm{mm})$

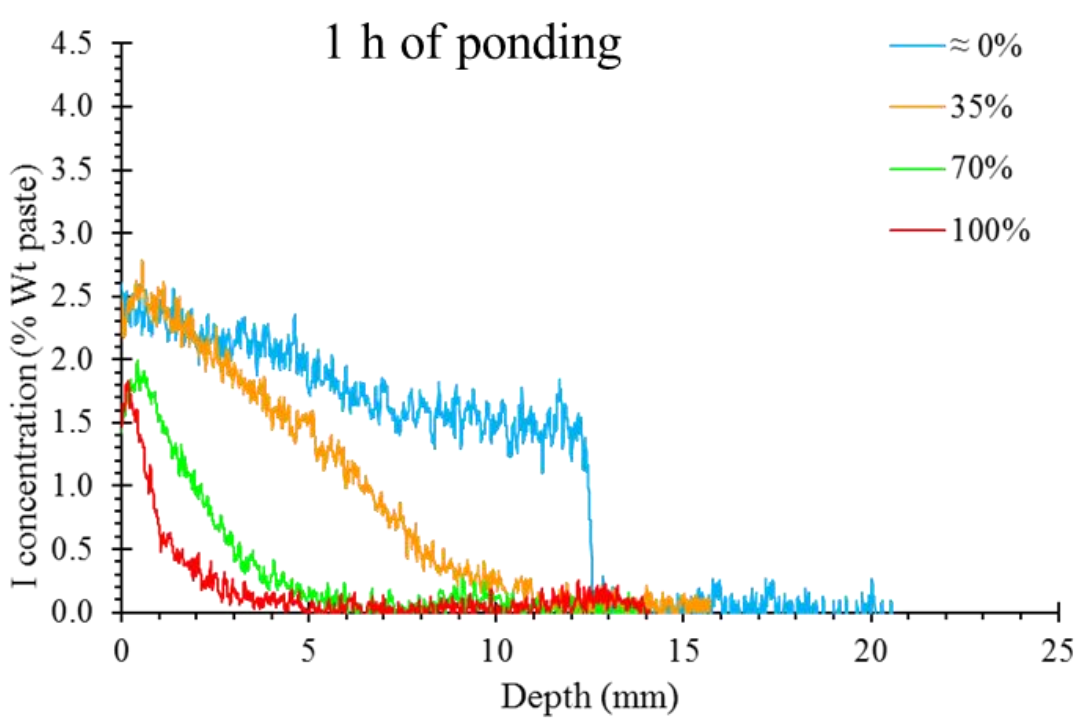

Fig. 7. TXM comparison of I penetration in different RH after $1 \mathrm{~h}$ ponding. 


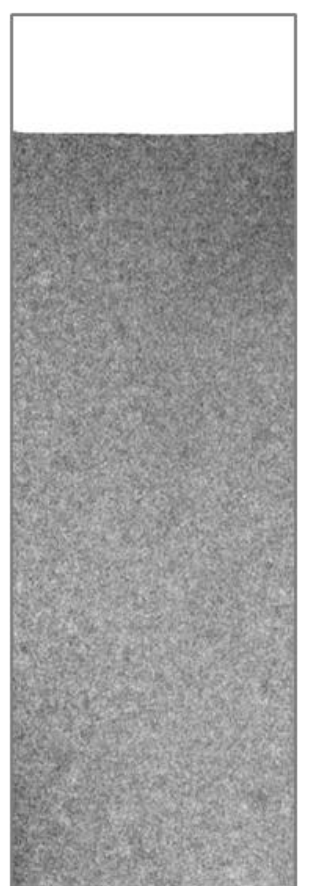

$\approx 0 \% \mathrm{RH}$

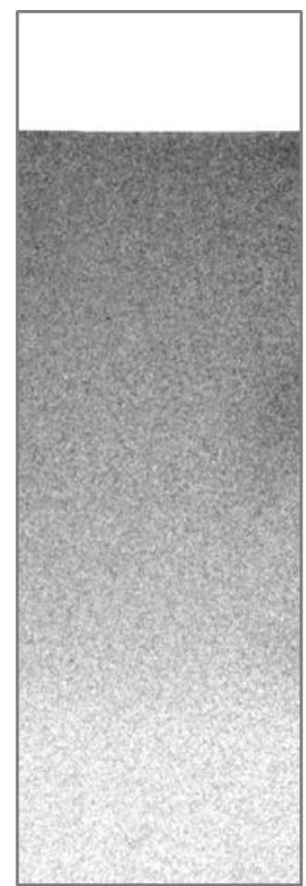

$35 \% \mathrm{RH}$

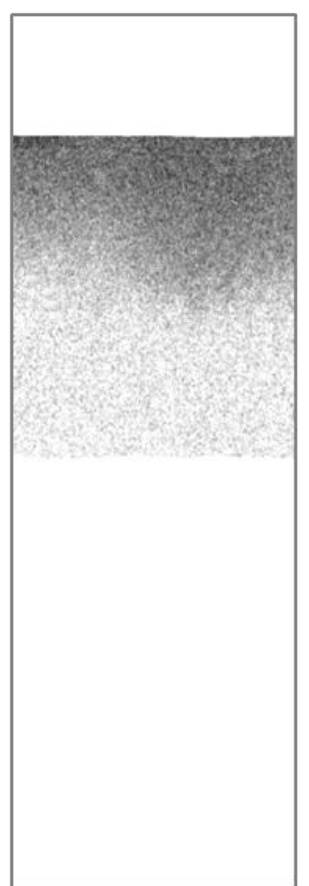

$70 \% \mathrm{RH}$

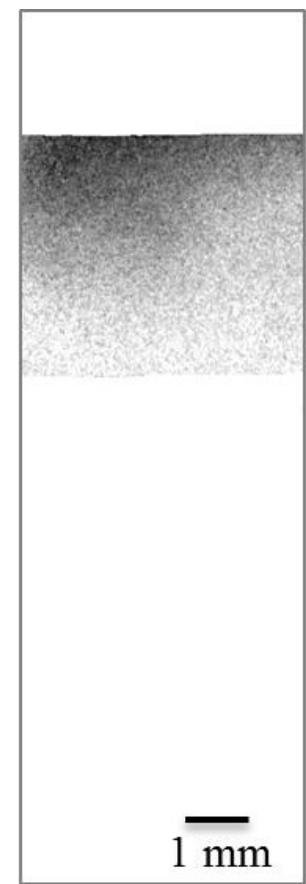

$100 \% \mathrm{RH}$

I penetration depth $(\mathrm{mm})$

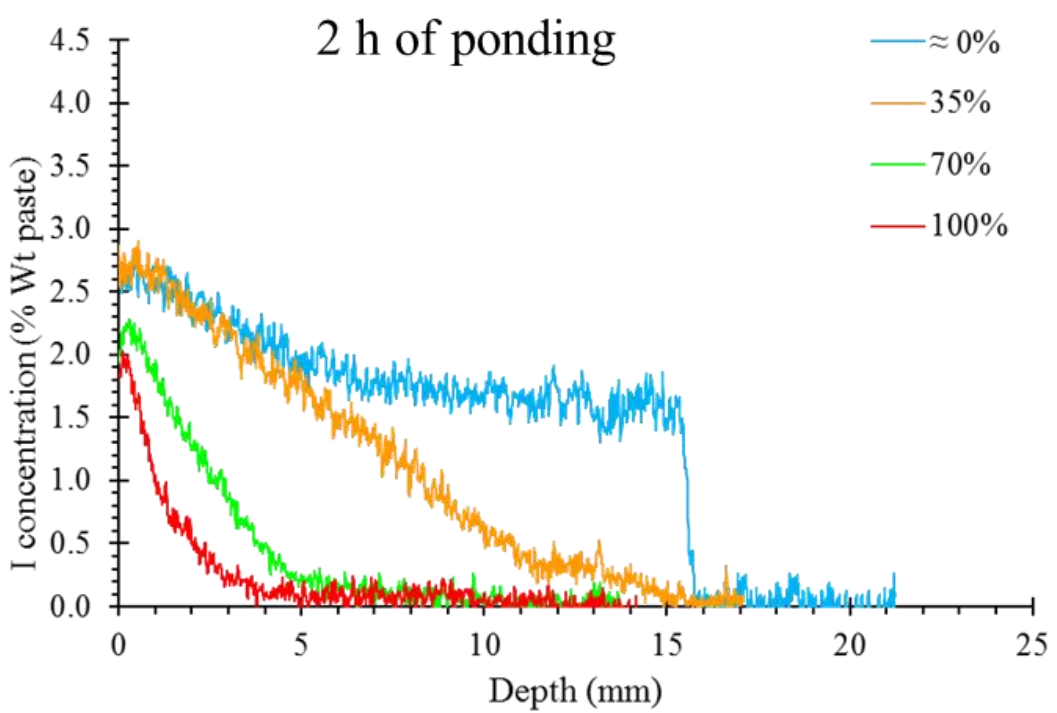

Fig. 8. TXM comparison of I penetration in different $\mathrm{RH}$ after $2 \mathrm{~h}$ ponding. 


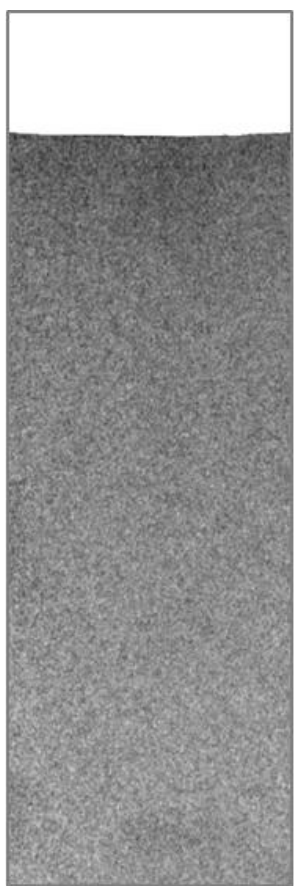

$\approx 0 \% \mathrm{RH}$

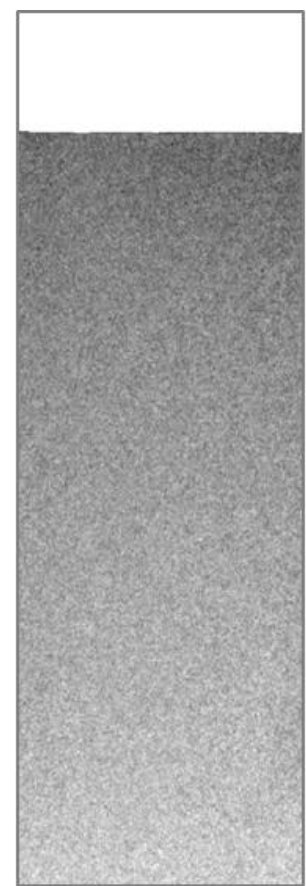

$35 \% \mathrm{RH}$

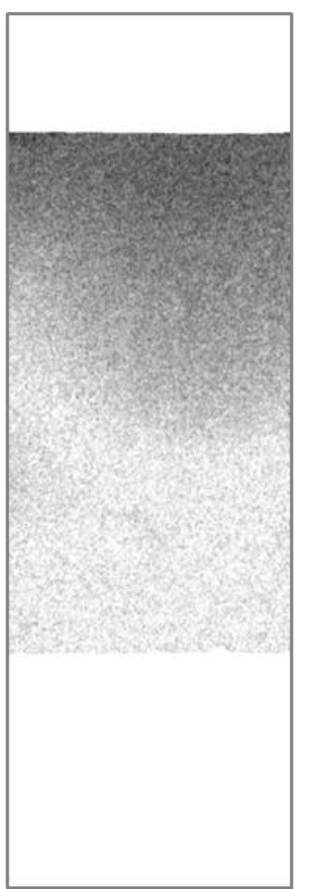

$70 \% \mathrm{RH}$

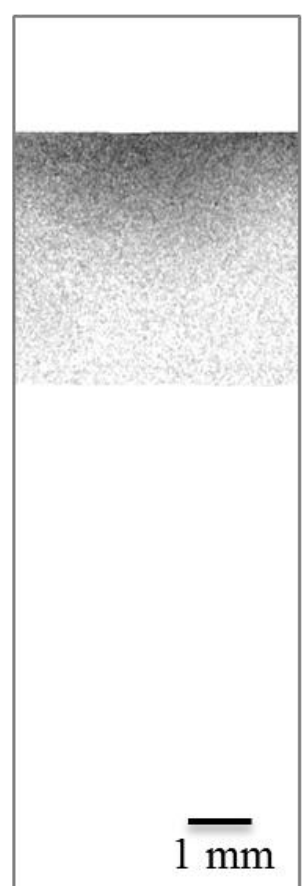

$100 \% \mathrm{RH}$

I penetration depth $(\mathrm{mm})$

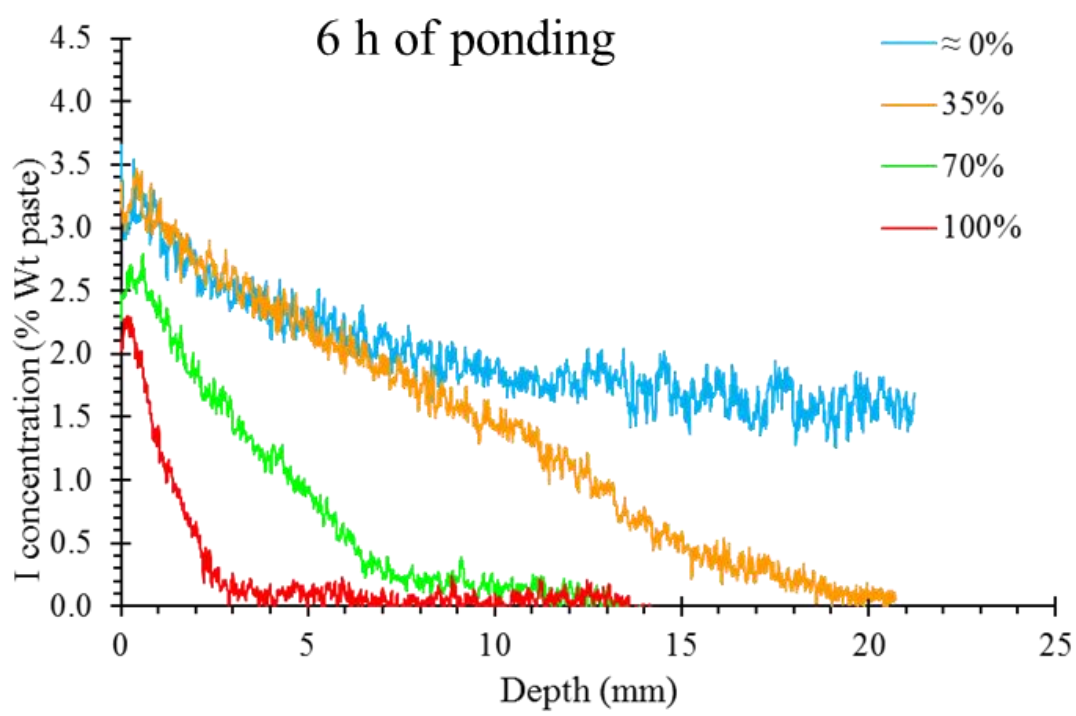

Fig. 9. TXM comparison of I penetration in different $\mathrm{RH}$ after $6 \mathrm{~h}$ ponding. *The ion penetrated through the entire scan depth. 


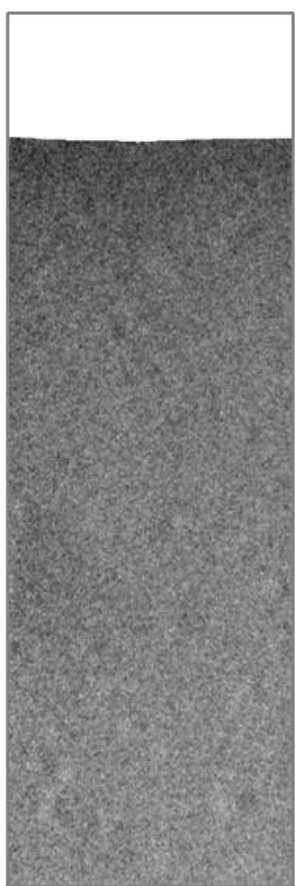

$\approx 0 \% \mathrm{RH}$

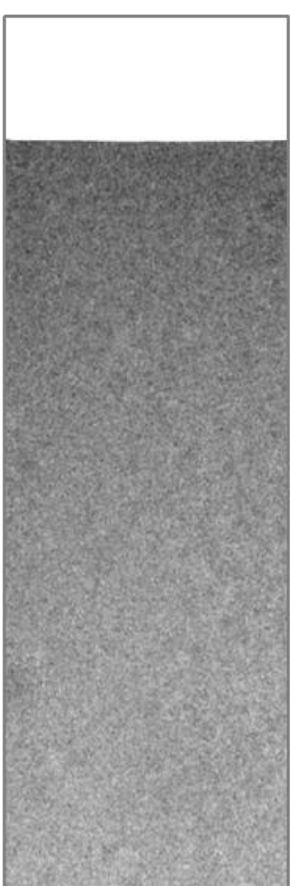

$35 \% \mathrm{RH}$

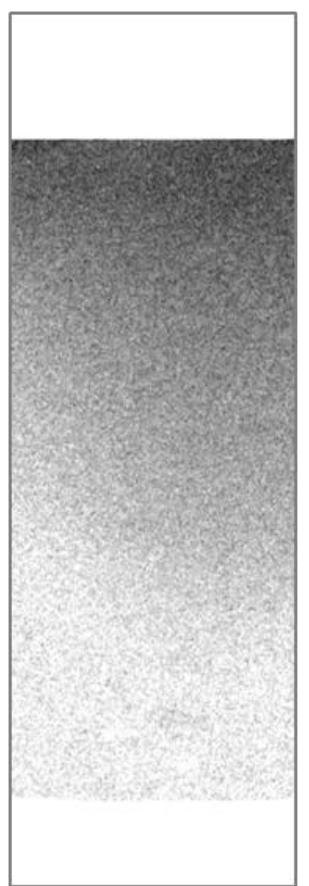

$70 \% \mathrm{RH}$

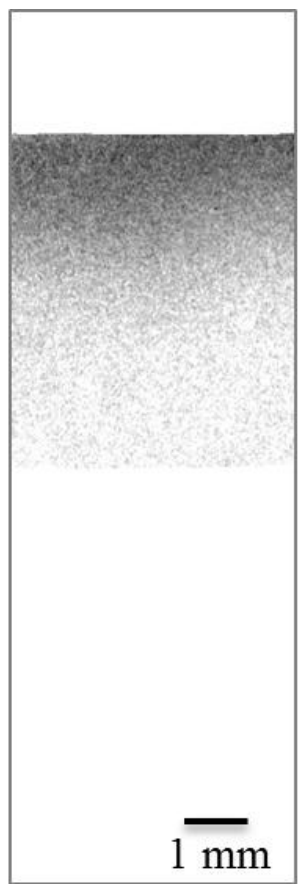

$100 \% \mathrm{RH}$

I penetration depth $(\mathrm{mm})$

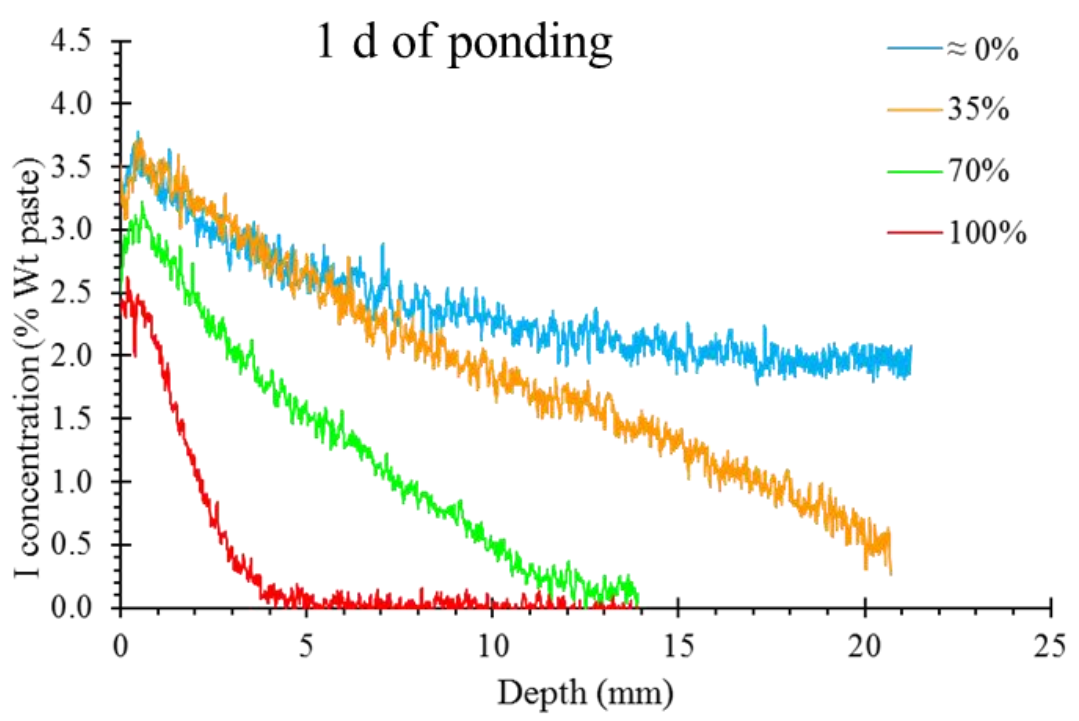

Fig. 10. TXM comparison of I penetration in different RH after $1 \mathrm{~d}$ ponding. 


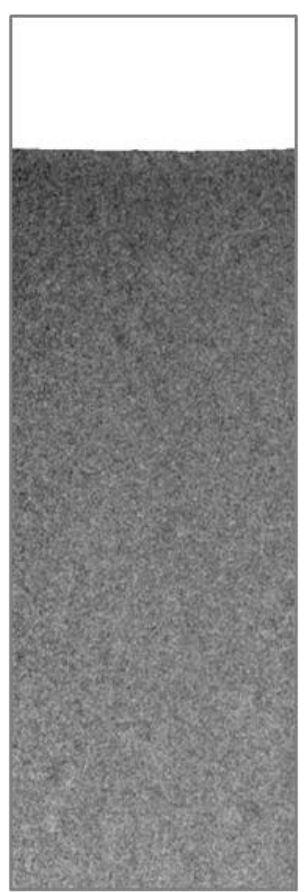

$\approx 0 \% \mathrm{RH}$

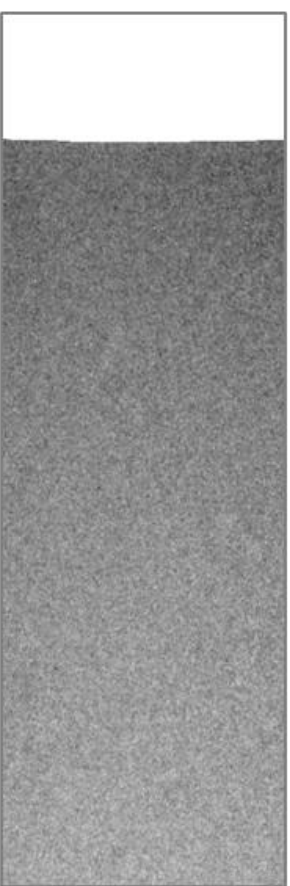

$35 \% \mathrm{RH}$

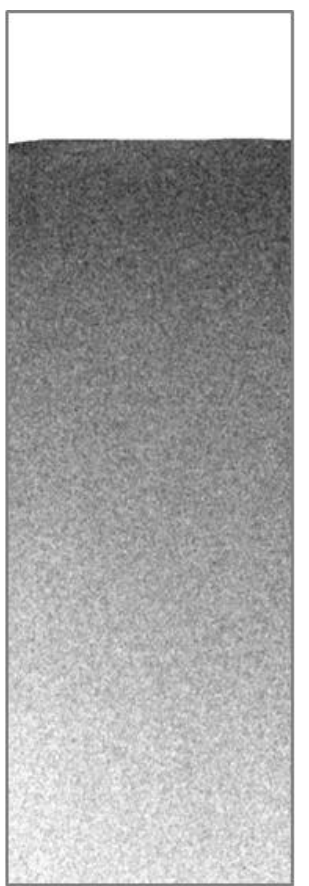

$70 \% \mathrm{RH}$

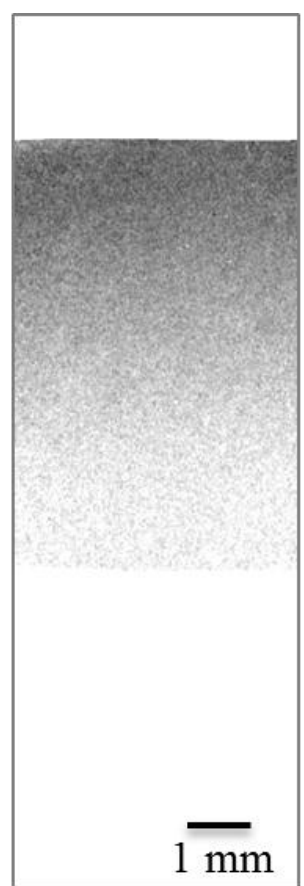

$100 \% \mathrm{RH}$

I penetration depth $(\mathrm{mm})$

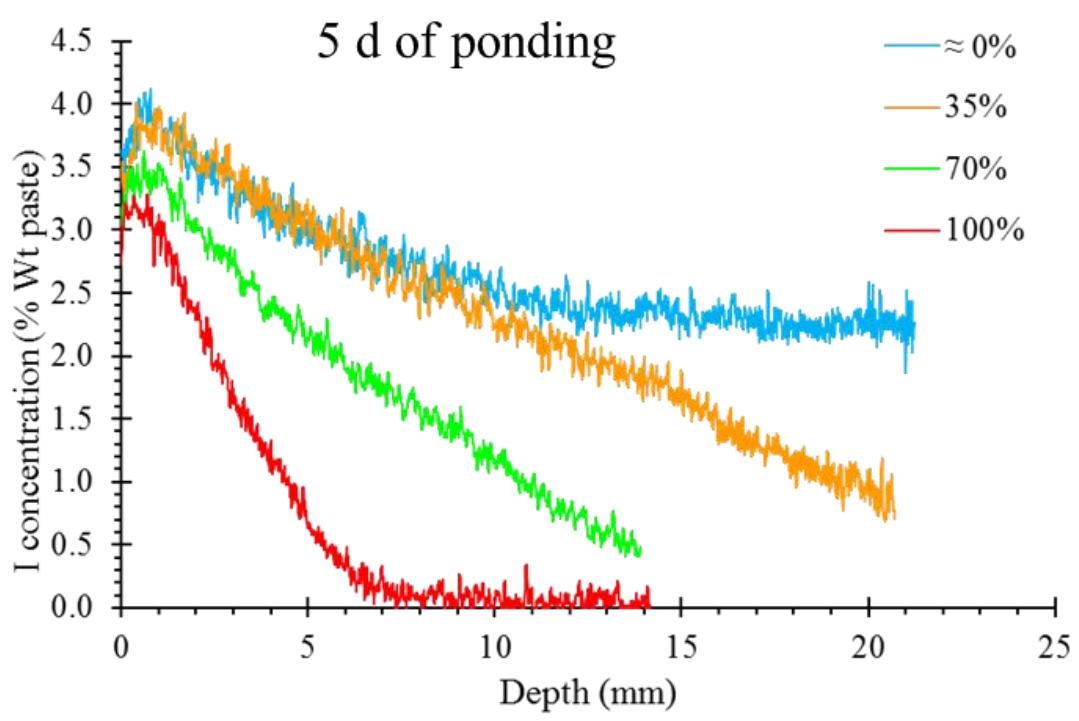

Fig. 11. TXM comparison of I penetration in different RH after $5 \mathrm{~d}$ ponding. 


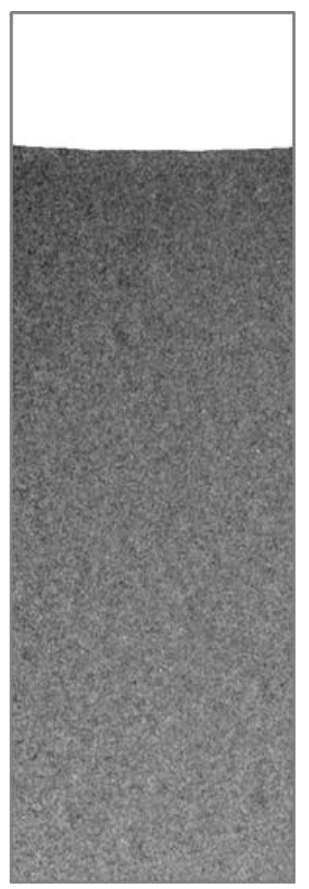

$\approx 0 \% \mathrm{RH}$

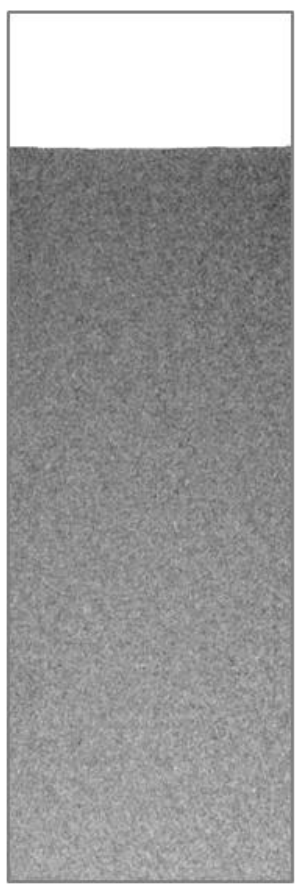

$35 \% \mathrm{RH}$

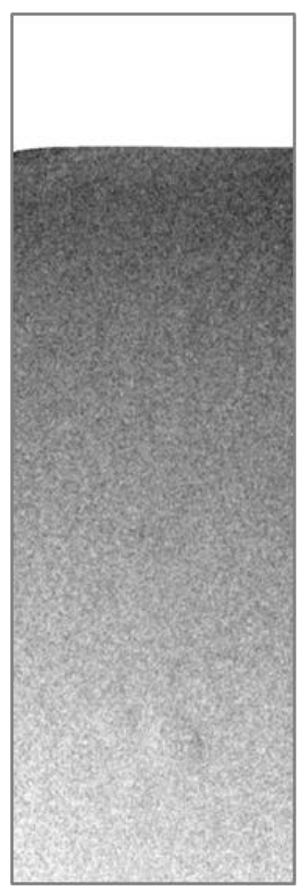

$70 \% \mathrm{RH}$

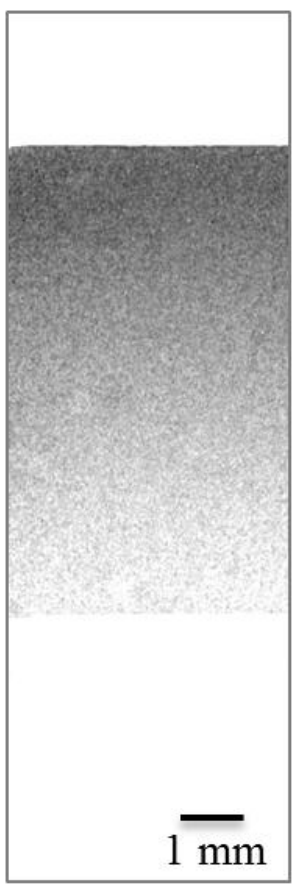

$100 \% \mathrm{RH}$

I penetration depth $(\mathrm{mm})$

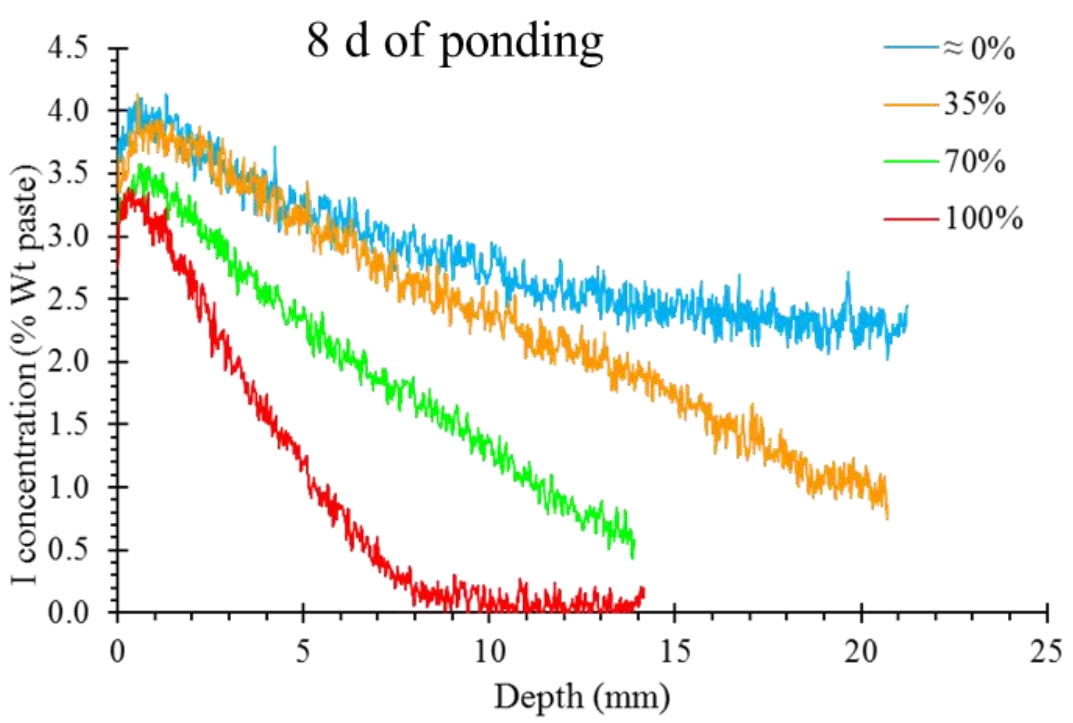

Fig. 12. TXM comparison of I penetration in different RH after $8 \mathrm{~d}$ ponding. 


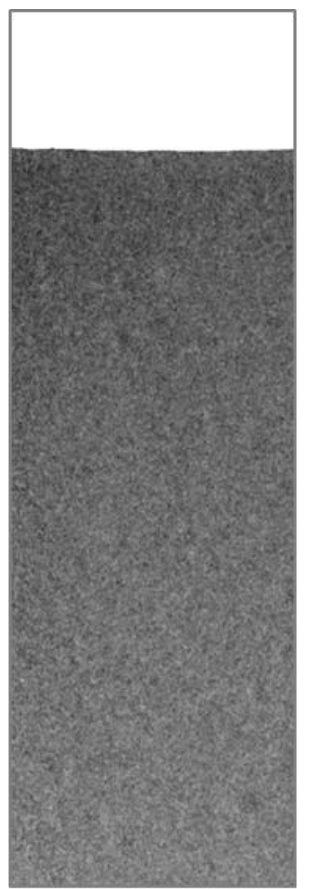

$\approx 0 \% \mathrm{RH}$

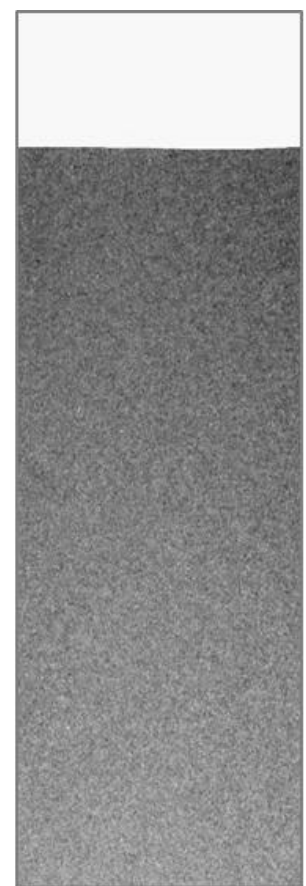

$35 \% \mathrm{RH}$

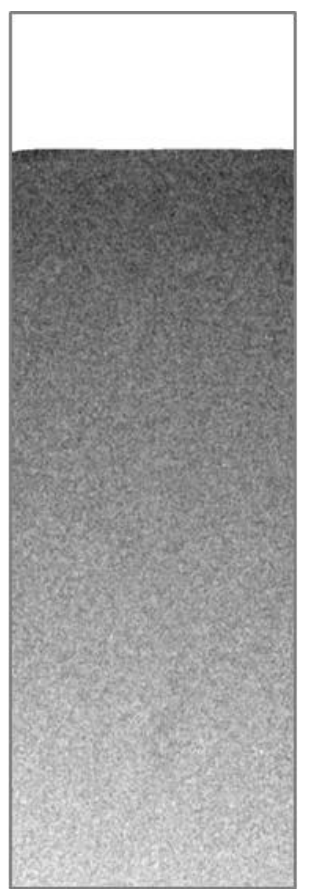

$70 \% \mathrm{RH}$

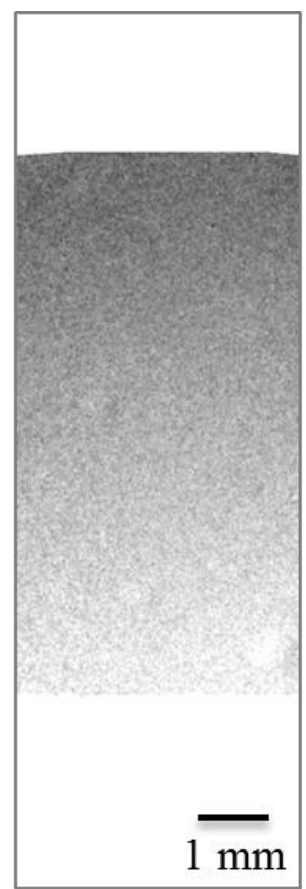

$100 \% \mathrm{RH}$

I penetration depth $(\mathrm{mm})$

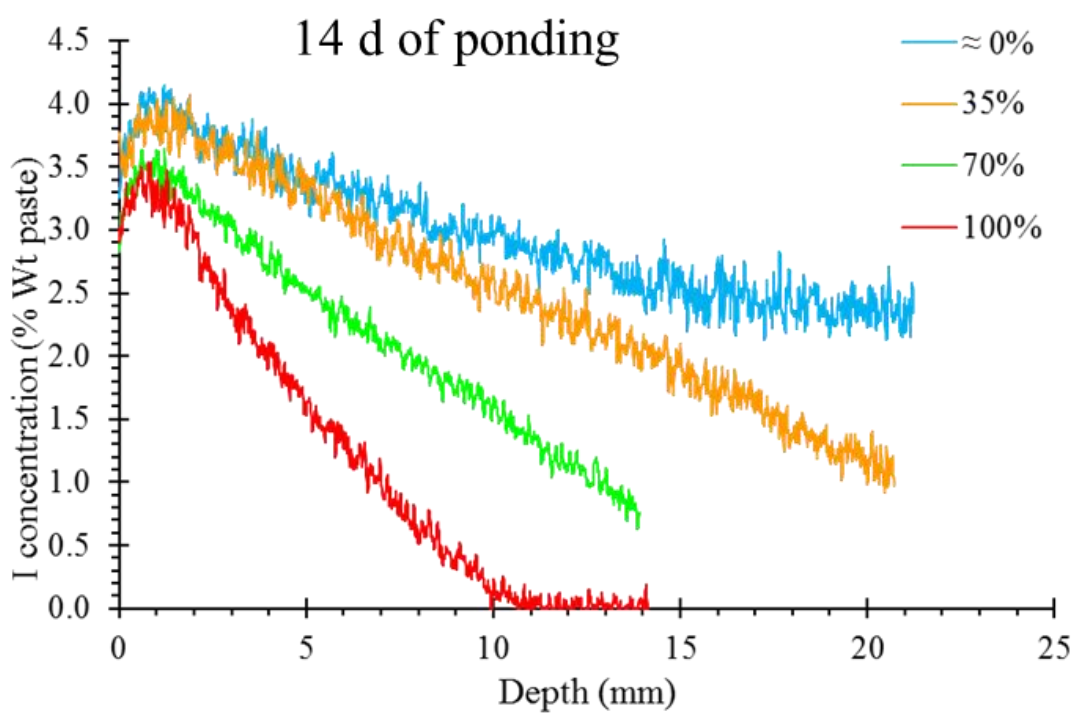

Fig. 13. TXM comparison of I penetration in different $\mathrm{RH}$ after $14 \mathrm{~d}$ ponding. 


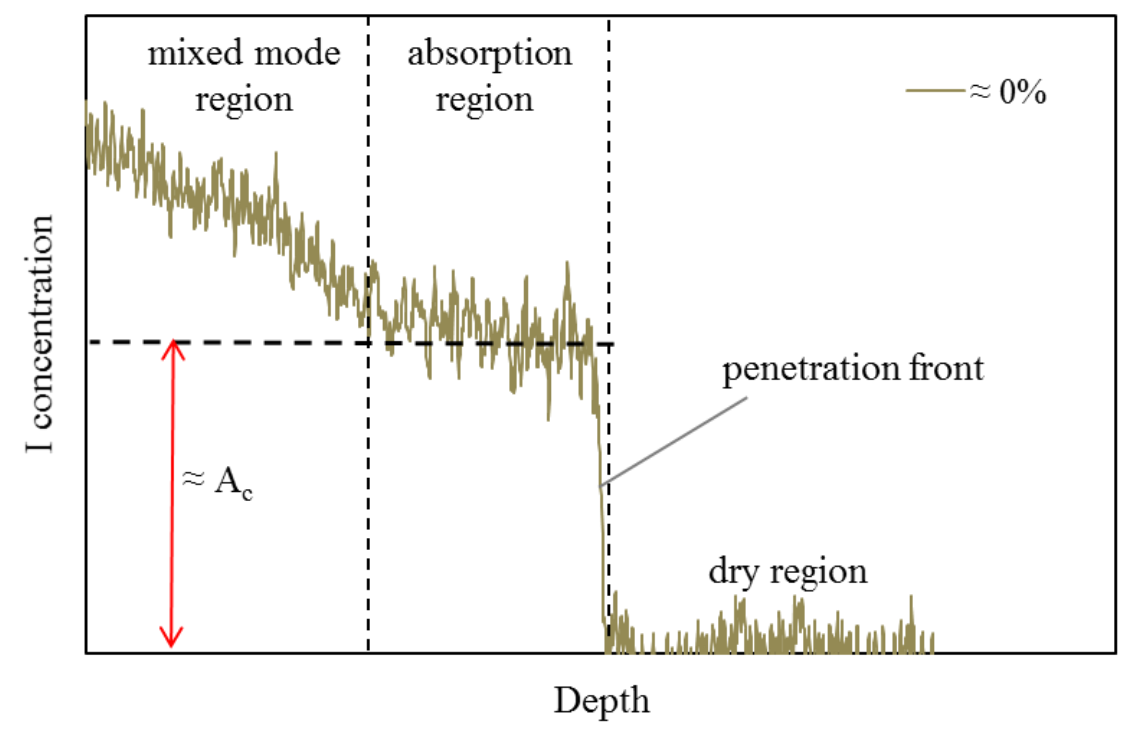

Fig. 14. An example of two modes I penetration in $\approx 0 \%$ RH sample.

\subsection{Comparison of TXM Results with Gravimetric Method}

Figure 15 compares the I penetration depths from TXM with calculated penetration depths from gravimetric measurements based on Eq. (3) over the first $6 \mathrm{~h}$ of ponding. In addition, the calculated sorptivity coefficients from both techniques based on Eq. (4) are summarized in Table 9. Based on Fig. 15, Eq. (3) underestimates the estimated penetration depth when compared to the measured penetration depths from TXM. These differences show an even wider variation over time. This difference is about $23 \%$ on average for samples with different DoS after $6 \mathrm{~h}$ of ponding. In addition, the average difference between the calculated sorptivity coefficients and the correction constants (B) of different samples from TXM and gravimetric method is about $25 \%$. Again, the gravimetric method underestimates the sorptivity coefficient in all of the samples conditioned in different RHs compared to TXM results. Consequently, the use of these equations would overestimate the service life of concrete structures. This difference can be attributed to the generalized assumption of the simplified capillary pore structure made in Eq. (3). 


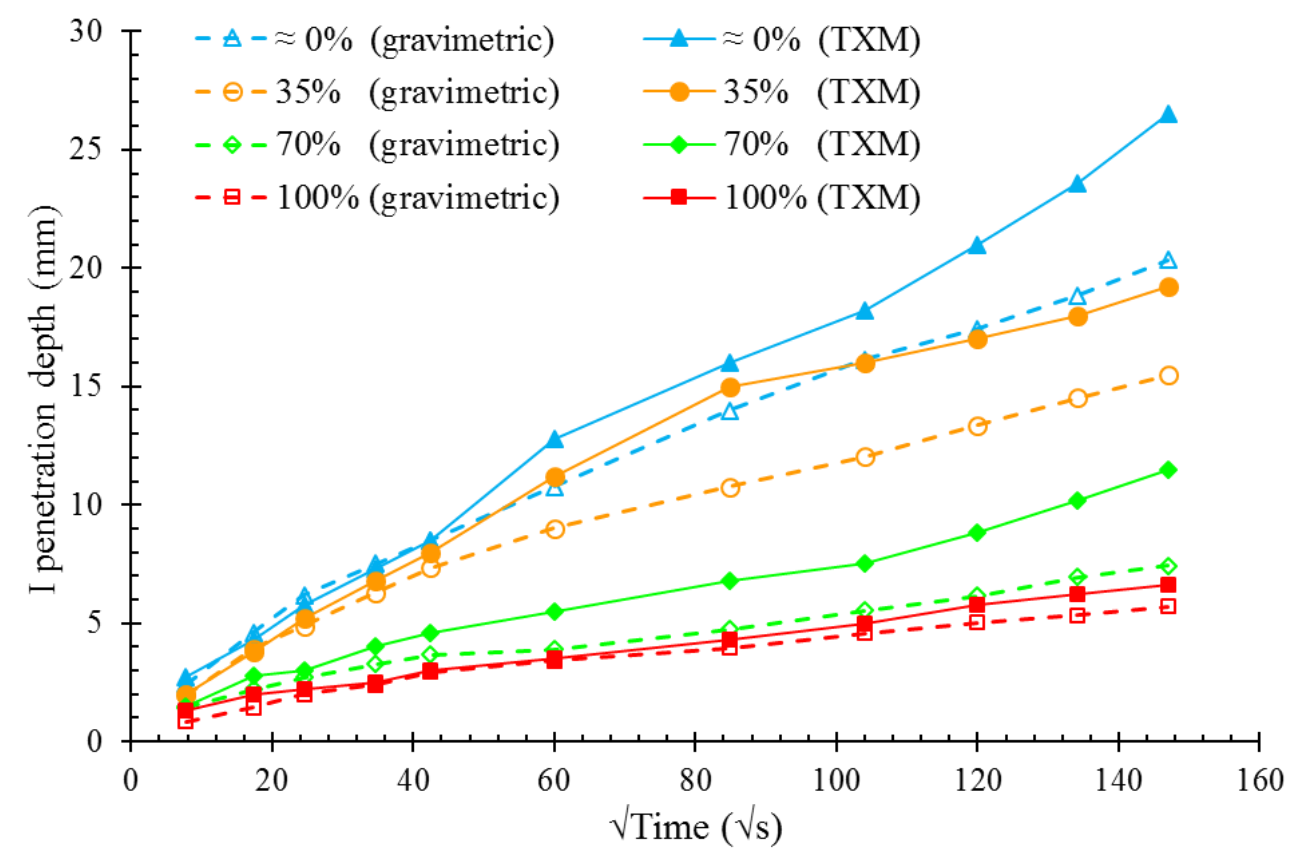

Fig. 15. Comparison between I penetration depths from TXM and gravimetric method.

Table 9. Comparison between I sorptivity values from TXM and gravimetric method

\begin{tabular}{|c|c|c|c|c|}
\hline RH & parameter & gravimetric & TXM & $\begin{array}{c}\% \text { difference } \\
(\mathrm{GV}-\mathrm{TXM}) \\
/(\mathrm{TXM} \times 0.01)\end{array}$ \\
\hline \multirow{3}{*}{$\approx 0 \%$} & $\mathrm{~S}(\mathrm{~mm} / \sqrt{ } \mathrm{s})$ & 0.123 & 0.1653 & -25.59 \\
\hline & $\mathrm{B}(\mathrm{mm})$ & 2.835 & 1.672 & 69.56 \\
\hline & $\mathrm{R}^{2}$ & 0.99 & 0.99 & \\
\hline \multirow{3}{*}{$35 \%$} & $\mathrm{~S}\left(\mathrm{~mm} / \sqrt{ }_{\mathrm{s}}\right)$ & 0.0902 & 0.1229 & -26.61 \\
\hline & $\mathrm{B}(\mathrm{mm})$ & 2.686 & 2.431 & 10.49 \\
\hline & $\mathrm{R}^{2}$ & 0.98 & 0.97 & \\
\hline \multirow{3}{*}{$70 \%$} & $\mathrm{~S}\left(\mathrm{~mm} / \sqrt{ }_{\mathrm{s}}\right)$ & 0.0392 & 0.0645 & -39.22 \\
\hline & $\mathrm{B}(\mathrm{mm})$ & 1.593 & 1.467 & 8.59 \\
\hline & $\mathrm{R}^{2}$ & 0.99 & 0.99 & \\
\hline \multirow{3}{*}{$100 \%$} & $\mathrm{~S}(\mathrm{~mm} / \sqrt{ } \mathrm{s})$ & 0.0325 & 0.0369 & -11.92 \\
\hline & $\mathrm{B}(\mathrm{mm})$ & 1.129 & 1.253 & -9.89 \\
\hline & $\mathrm{R}^{2}$ & 0.97 & 0.99 & \\
\hline
\end{tabular}

3.5 Time-dependent I Penetration Coefficient 
Figure 16 displays time-dependent I penetration coefficient based on Eq. (7) for cement paste samples conditioned at 35\%, 70\%, and 100\% RH from TXM. As explained earlier, the calculated $\mathrm{P}_{\mathrm{c}}$ considers the combined effect from capillary absorption and diffusion in partiallysaturated samples. The calculated $\mathrm{P}_{\mathrm{c}}$ and $\mathrm{A}_{\mathrm{c}}$ of the $\approx 0 \% \mathrm{RH}$ sample based on Eq. (7) is shown in Fig. 17 over time. Based on Fig. 16, the $\mathrm{P}_{\mathrm{c}}$ of $35 \%$ RH sample is about 40x the sample conditioned in $100 \% \mathrm{RH}$ at $2 \mathrm{~d}$ of ponding. This ratio decreases over time and reaches $11 \mathrm{x}$ after $14 \mathrm{~d}$ of ponding. The $70 \% \mathrm{RH}$ sample also has a higher $\mathrm{P}_{\mathrm{c}}$ when compared to $100 \% \mathrm{RH}$ sample $\left(\mathrm{P}_{\mathrm{c},(70 \%)} / \mathrm{P}_{\mathrm{c},(100 \%)}=10\right.$ at $2 \mathrm{~d}$ of ponding $)$. This can be caused by the early age combined transport mechanisms in partially-saturated samples. This highlights the importance of DoS in ion transport into cement-based materials.

As shown in Fig. 17, the ratio of $\mathrm{P}_{\mathrm{c}}$ of $\approx 0 \% \mathrm{RH}$ to $\mathrm{P}_{\mathrm{c}}$ of $100 \% \mathrm{RH}$ is about 12 at $2 \mathrm{~d}$ of ponding. This ratio decreases to 4 after $14 \mathrm{~d}$ of ponding. As mentioned earlier, the calculated $\mathrm{P}_{\mathrm{c}}$ of $\approx 0 \%$ RH sample based on Eq. (7) does not take into account the effect of capillary absorption. Therefore, the calculated $\mathrm{P}_{\mathrm{c}}$ for $\approx 0 \% \mathrm{RH}$ sample is not directly comparable with $\mathrm{P}_{\mathrm{c}}$ of other partially-saturated samples. Furthermore, the calculated $\mathrm{P}_{\mathrm{c}}$ of $\approx 0 \% \mathrm{RH}$ sample shows a decreasing rate until $7 \mathrm{~d}$ of ponding, then it starts to slightly increase from $7 \mathrm{~d}$ to $14 \mathrm{~d}$ of ponding. The $A_{c}$ constant, which accounts for the effect of capillary absorption, also decreases from $7 \mathrm{~d}$ to $14 \mathrm{~d}$ of ponding. This could be caused by a change from capillary absorption to diffusion in the $\approx$ $0 \% \mathrm{RH}$ samples after $7 \mathrm{~d}$ of ponding. It has been reported that capillary forces decrease after 24 $\mathrm{h}$ from ponding resulting from the increasing DoS and further penetration of ions occurs as a result of diffusion process [38]. 


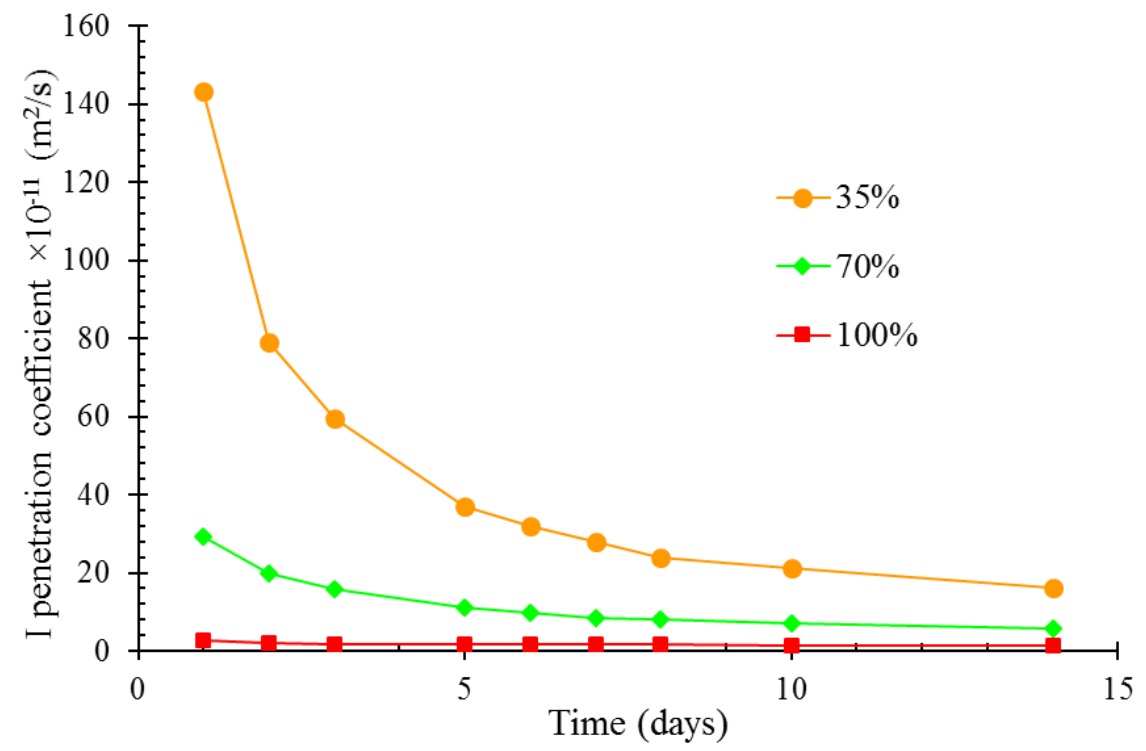

Fig. 16. Time-dependent I penetration coefficients of 35\%, 70\%, and 100\% RH samples by TXM.

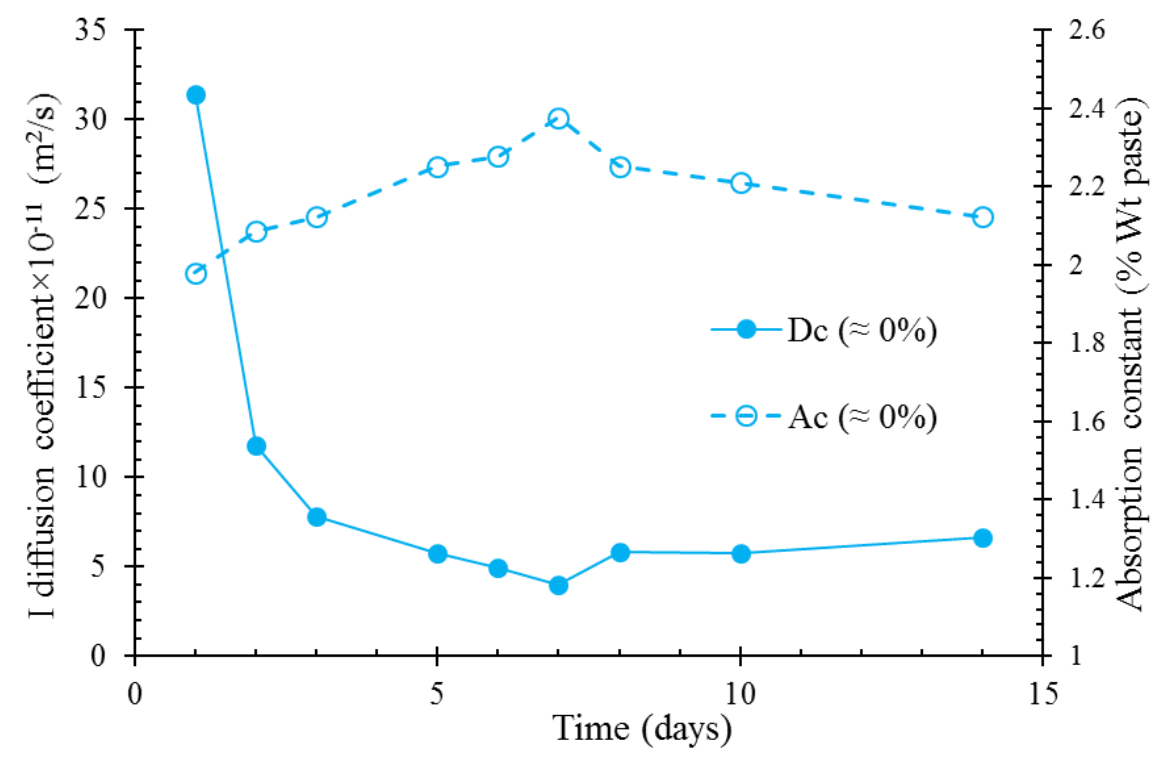

Fig. 17. Time-dependent $P_{c}$ and $A_{c}$ for $\approx 0 \%$ RH samples by TXM; estimated by using Eq. (7). $P_{c}$ is penetration coefficient and $A_{c}$ is the capillary absorption constant.

In addition, a power model based on the experimental results is shown in Eq. (8) to estimate the $P_{c}$ of partially-saturated paste samples with w/c of 0.40 from a fully saturated sample, as formulated in Eq. (8). 
$\frac{P_{h}}{P_{100 \%}}=a \times t^{-\left(1-\frac{h}{100}\right)}$

where $\mathrm{P}_{\mathrm{h}}$ is the penetration coefficient of the sample conditioned at relative humidity of $\mathrm{h}$, which accounts for the combined transport mechanisms from capillary absorption and diffusion; $\mathrm{P}_{100 \%}$ is penetration coefficient of the sample conditioned at $100 \% \mathrm{RH}$; $\mathrm{t}$ denotes the time; and a is the regression constant. The regression results for 35\% and 70\% RH samples are summarized in Fig. 18. Based on Fig. 18, there is good correlation between the developed model and experimental results. The regression constant, "a", decreases with the increase of DoS in the sample.

Additional work is needed to extend Eq. (8) to other RH and mixture proportions. This model could be used in computational modeling efforts to predict the service life of concrete structures in harsh environments.

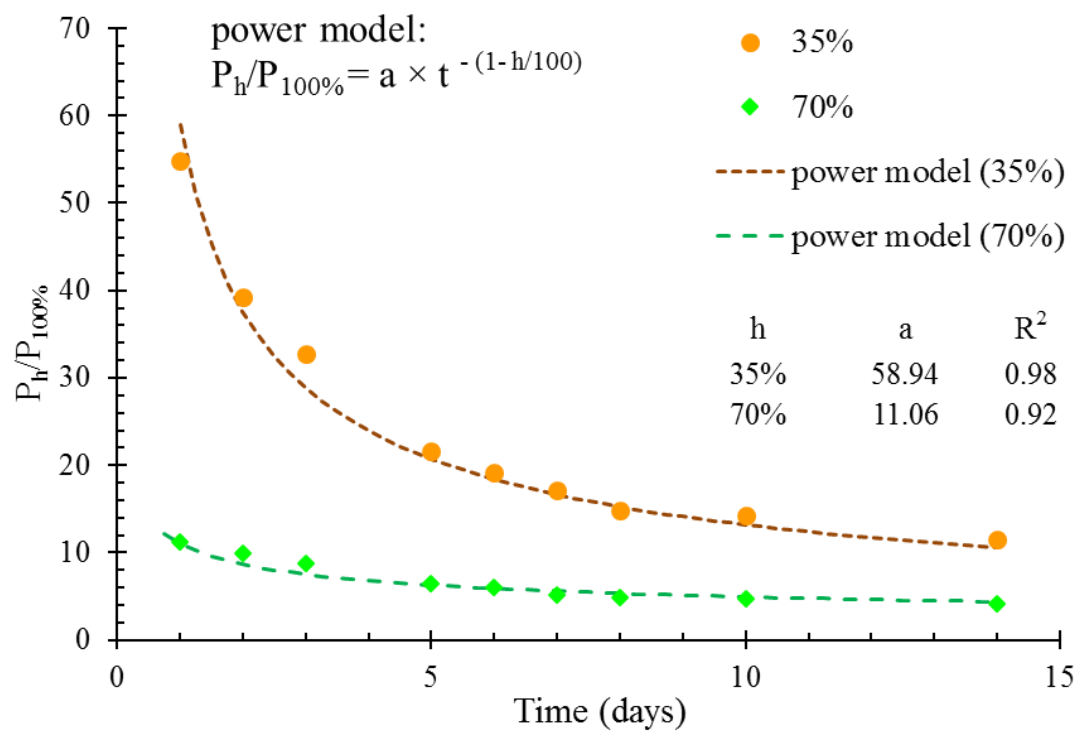

Fig. 18. A power model to estimate time-dependent penetration coefficients of $35 \%$ and $70 \% \mathrm{RH}$ samples from $100 \%$ RH results.

3.6 Practical Implications 
This work provides quantitative insights into the penetration of ions into cement paste at different moisture conditions. Typically, laboratory testing is carried out at $100 \% \mathrm{RH}$ and the results from the testing are used to predict the long-term resistance to $\mathrm{Cl}$ penetration. This work provides important data that makes quantitative measurements of how partially-saturated samples perform in these tests and shows that rate of penetration is higher in these situations. Furthermore, a power model has been presented that would allow testing results from saturated samples to be used to predict performance in partially-saturated materials. This is a useful contribution to the literature. Although more work is needed to extend these findings to different materials and conditions, this work is an important step to improve our predictive powers of the durability of concrete infrastructure. Furthermore, the findings from this work show that the previously suggested equation to estimate the depth of ion transport based on ASTM C 1585 is unconservative by $\approx 23 \%$ for the materials and conditions investigated.

\section{Conclusions}

The presented work uses a non-destructive and rapid imaging method to investigate insitu and time resolved I penetration into cement paste samples with different DoS. The sorptivity of $\mathrm{Cl}$ and $\mathrm{I}$ ions in paste samples was also determined gravimetrically and compared with the TXM results. In addition, the same samples from TXM and gravimetric methods were also examined with $\mu \mathrm{XRF}$ in order to verify their results and compare the I and $\mathrm{Cl}$ penetration. Furthermore, time-series I concentration profiles and penetration depths with $8.8 \mu$ m resolution from TXM were used to obtain sorptivity and penetration coefficients at different conditions and to observe important insights about combined ion transport mechanisms in partially-saturated samples. This work also suggests a modified version of the simplified solution to Fick's second law to take into account the capillary absorption and complex penetration of outside chemicals 
into cement paste. A constant value, known as the absorption coefficient $\left(\mathrm{A}_{\mathrm{c}}\right)$, was added to the simplified solution of Fick's second law that can account for the initial uptake or absorption of the fluid into the $\approx 0 \% \mathrm{RH}$ sample.

The following conclusions can be drawn from this work:

- The samples conditioned at $\approx 0 \%$ and $35 \%$ RHs showed about 3.6X more penetration of I compared to saturated samples at $1 \mathrm{~h}$ of ponding.

- After only $6 \mathrm{~h}$ of ponding for the $\approx 0 \%$ and $35 \% \mathrm{RH}$ samples the I was observed to penetrate over $20 \mathrm{~mm}$.

- The initial penetration of I into the $\approx 0 \% \mathrm{RH}$ sample shows an almost constant concentration of $2 \%$ I by weight of the paste. This is likely due to capillary suction.

- Over time the concentration profile at the surface of the $\approx 0 \% \mathrm{RH}$ sample continues to increase suggesting that there are other modes of ion penetration controlling the rate of penetration.

- The 35\% and 70\% RH samples show a 40x and 10x increase respectively in the penetration coefficient over the fully saturated sample at early ages ( $2 \mathrm{~d}$ of ponding). However, this ratio decreases over time. This can be caused by the early age combined transport mechanisms in partially-saturated samples.

- Previously suggested equations to estimate the depth of ion transport based on gravimetric analysis were found to be unconservative by $\approx 23 \%$ for the materials and conditions investigated and this may cause an overestimation of the predicted service life.

- A power model was successfully used to estimate the $\mathrm{P}_{\mathrm{c}}$ of partially-saturated paste samples based on the $\mathrm{P}_{\mathrm{c}}$ of fully saturated samples. 
- Iodide shows $\mathrm{a} \approx 15 \%$ difference in sorptivity coefficient and $\approx 6 \%$ difference in penetration coefficient compared to $\mathrm{Cl}$ in samples with different DoS.

- There was a $4 \%$ difference found between the calculated $\mathrm{P}_{\mathrm{c}}$ from the $\mu \mathrm{XRF}$ and TXM techniques and the results between the two methods were found to be statistically comparable.

The use of TXM offers advantages over conventional methods to investigate the effect of DoS for ion penetration into cement-based materials with a number of different conditions. Since TXM allows non-destructive and time-dependent concentration profiles to be measured with little sample preparation, TXM can be used to measure the evolution of the penetration over time. These findings show promise to help refine service life modeling techniques for concrete materials and to ultimately improve the predictive capabilities of the lifetime of concrete structures. This data quantifies the impacts of partial saturation on ion transport and shows that even partial drying of concrete will increase the penetration of outside ions through mixed modes of mass transport. This can help owners in dry environments better predict and maintain their concrete structures. Additional modeling efforts are underway to provide additional insights.

\section{Acknowledgments}

The authors acknowledge the financial support from the Oklahoma Department of Transportation (ODOT 2229), Federal Highway Association (FHWA) Exploratory Advanced Research (EAR) Program (Project No. CMMI 1030972), and the United States National Science Foundation CMMI 1635878 and CMMI 1150404 CAREER Award. The authors would also like to recognize their collaborators Dr. Kimberly Kurtis, Dr. Lisa Burris, and Prasanth Alapati of Georgia Tech, Dr. Neal Berke of Tourney Consulting and Dr. Robert Moser of the US Army Corps of Engineers for their assistance and discussion on this work. 


\section{References}

[1] G.H. Koch, M.P. Brongers, N.G. Thompson, Y.P. Virmani, J.H. Payer, Corrosion costs and preventive strategies in the United States, Report by CC Technologies Laboratories, Inc. to Federal Highway Administration (FHWA)-RD-01-151, September 2001.

[2] P.K. Mehta, Durability of Concrete- Fifty Years of Progress?, ACI SP 126-1, (1991) 1-31.

[3] M. Khanzadeh-moradllo, M.H. Meshkini, E. Eslamdoost, S. Sadati, M. Shekarchi, Effect of Wet Curing Duration on Long-Term Performance of Concrete in Tidal Zone of Marine Environment, Int. J. Concr. Struct. Mater. (2015). doi:10.1007/s40069-015-0118-3.

[4] M. Khanzadeh Moradllo, M. Shekarchi, M. Hoseini, Time-dependent performance of concrete surface coatings in tidal zone of marine environment, Constr. Build. Mater., 30 (2012), 198-205 http://dx.doi.org/10.1016/j.conbuildmat.2011.11.044.

[5] S. Sadati, M. Arezoumandi, M. Shekarchi, Long-term performance of concrete surface coatings in soil exposure of marine environments, Constr. Build. Mater. 94 (2015) 656-663. doi:10.1016/j.conbuildmat.2015.07.094.

[6] M. Khanzadeh Moradllo, B. Sudbrink, M.T. Ley, Determining the effective service life of silane treatments in concrete bridge decks, Constr. Build. Mater., 116 (2016), 121-127 http://dx.doi.org/10.1016/j.conbuildmat.2016.04.132.

[7] S. Lu, E.N. Landis, D.T. Keane, X-ray microtomographic studies of pore structure and permeability in Portland cement concrete, Mater. Struct. 39 (2007) 611-620. doi:10.1617/s11527-006-9099-7.

[8] G. Sant, W.J. Weiss, Using X-Ray Absorption to Assess Moisture Movement in CementBased Materials, J. ASTM Int. 6 (2009) 15. doi:10.1520/JAI102234.

[9] C. Hall, Water sorptivity of mortars and concretes: a review, Mag. Concr. Res. 41 (1989) 5161.

[10] N.S. Martys, C.E. Ferraris, Capillary transport in mortars and concrete, Cem. Concr. Res. 27 (1997) 747-760.

[11] J. Castro, D. Bentz, J. Weiss, Effect of sample conditioning on the water absorption of concrete, Cem. Concr. Comp. 33 (2011) 805-813. doi:10.1016/j.cemconcomp.2011.05.007.

[12] B. Van Belleghem, R. Montoya, J. Dewanckele, N. Van Den Steen, I. De Graeve, J. Deconinck, Capillary water absorption in cracked and uncracked mortar - A comparison between experimental study and finite element analysis, Constr. Build. Mater. 110 (2016) 154162. doi:10.1016/j.conbuildmat.2016.02.027. 
[13] M. Janz, Methods of Measuring the Moisture Diffusivity at High Moisture Levels, Licentiate Thesis, University of Lund, 1997.

[14] V. Cnudde, M. Dierick, J. Vlassenbroeck, B. Masschaele, High-speed neutron radiography for monitoring the water absorption by capillarity in porous materials, NIM B 266 (2008) 155163. doi:10.1016/j.nimb.2007.10.030.

[15] C. Lucero, Quantifying Moisture Transport in Cementitious Materials Using Neutron Radiography, In: MSc thesis, Purdue University, West Lafayette, Indiana, USA, 2015.

[16] H. Derluyn, M. Griffa, D. Mannes, I. Jerjen, J. Dewanckele, P. Vontobel, et al., Characterizing saline uptake and salt distributions in porous limestone with neutron radiography and X-ray micro-tomography, J. Build. Phys. 36 (2013) 353-374.

doi:10.1177/1744259112473947.

[17] C.L. Lucero, D.P. Bentz, D.S. Hussey, D.L. Jacobson, W.J. Weiss, Using Neutron Radiography to Quantify Water Transport and the Degree of Saturation in Entrained Air Cement Based Mortar (In Press), Phys. Procedia (10 World Conf. Neutron Radiogr. 69 (2014) 1-8. doi:10.1016/j.phpro.2015.07.077.

[18] D.P. Bentz, K.K. Hansen, Preliminary observations of water movement in cement pastes during curing using X-ray absorption, Cem. Concr. Res. 30 (2000) 1157-1168. doi:10.1016/s0008-8846(00)00273-8.

[19] S. Roels, J. Carmeliet, Analysis of moisture flow in porous materials using microfocus Xray radiography, Int. J. Heat Mass Transf. 49 (2006) $4762-4772$.

doi:10.1016/j.ijheatmasstransfer.2006.06.035.

[20] M. A. Hickner, N.P. Siegel, K.S. Chen, D.S. Hussey, D.L. Jacobson, M. Arif, In Situ HighResolution Neutron Radiography of Cross-Sectional Liquid Water Profiles in Proton Exchange Membrane Fuel Cells, J. Electrochem. Soc. 155 (2008) B427. doi:10.1149/1.2826287.

[21] I.S. Darma, T. Sugiyama, M.A.B. Promentilla, Application of X-Ray CT to Study Diffusivity in Cracked Concrete Through the Observation of Tracer Transport, J. Adv. Concr. Technol. 11 (2013) 266-281. doi:10.3151/jact.11.266.

[22] V.C. Tidwell, L.C. Meigs, T. Christian-Frear, C.M. Boney, Effects of spatially heterogeneous porosity on matrix diffusion as investigated by X-ray absorption imaging, J. Contam. Hydrol. 42 (2000) 285-302. doi:10.1016/S0169-7722(99)00087-X.

[23] L. Cavé, T. Al, Y. Xiang, P. Vilks, A technique for estimating one-dimensional diffusion coefficients in low-permeability sedimentary rock using X-ray radiography: Comparison with through-diffusion measurements, J. Contam. Hydrol. 103 (2009) 1-12.

doi:10.1016/j.jconhyd.2008.08.001. 
[24] S.J. Altman, M. Uchida, V.C. Tidwell, C.M. Boney, B.P. Chambers, Use of X-ray absorption imaging to examine heterogeneous diffusion in fractured crystalline rocks, J. Contam. Hydrol. 69 (2004) 1-26. doi:10.1016/S0169-7722(03)00153-0.

[25] B. Sudbrink, M. Khanzadeh Moradllo, Q. Hu, M.T. Ley, J.M. Davis, N. Materer, A. Apblett, Imaging the presence of silane coatings in concrete with micro X-ray fluorescence. Cem. Concr. Res. 92 (2017) 121-127. http://dx.doi.org/10.1016/j.cemconres.2016.11.019.

[26] M. Khanzadeh Moradllo, B. Sudbrink, Q. Hu, M. Aboustait, B. Tabb, M.T. Ley, J.M. Davis, Using micro X-ray fluorescence to image chloride profiles in concrete. Cem. Concr. Res. 92 (2017) 128-141. http://dx.doi.org/10.1016/j.cemconres.2016.11.014.

[27] J.M. Davis, D.E. Newbury, A. Fahey, N.W.M. Ritchie, E. Vicenzi, D. Bentz, Bridging the micro-to-macro gap: a new application for micro X-ray fluorescence., Microsc. Microanal. 17 (2011) 410-417. doi:10.1017/S1431927611000183.

[28] J.M. Davis, D.E. Newbury, P.R. Rangaraju, S. Soundrapanian, C. Giebson, Milli X-ray fluorescence $\mathrm{X}$-ray spectrum imaging for measuring potassium ion intrusion into concrete samples, Cem. Concr. Compos. 31 (2009) 171-175. doi:10.1016/j.cemconcomp.2008.12.005.

[29] D. Bentz, M. Peltz, K. Snyder, J. Davis, VERDiCT: viscosity enhancers reducing diffusion in concrete technology, Concr. Int. 31 (2009) 31-36.

[30] D.P. Bentz, P.E. Stutzman, Curing, Hydration, and Microstructure of Cement Paste, ACI Mater. J. 103 (2006) 348-356.

[31] D.P. Bentz, Three-dimensional computer simulation of Portland cement hydration and microstructure development, J. Am. Ceram. Soc. 80 (1997) 3-21.

[32] M. Khanzadeh Moradllo, Q. Hu, M.T. Ley, Using X-ray imaging to investigate in-situ ion diffusion in cementitious materials. Constr. Build. Mater. 136 (2017) 88-98. http://dx.doi.org/10.1016/j.conbuildmat.2017.01.038

[33] M. Khanzadeh Moradllo, M.T. Ley, Comparing in-situ ion diffusion in Alternative Cementitious Materials by using X-ray imaging. Cem. Concr. Comp. (2016); Submitted for publication.

[34] Y. Farnam, T. Washington, J. Weiss, The influence of calcium chloride salt solution on the transport properties of cementitious materials, Advances in Civil Engineering 2015 (2015) 1-13.

[35] C. Hall, W.D. Hoff, Water-transport in brick, stone and concrete, second ed., CRC Press, London, 2009. 
[36] R.P. Spragg, J. Castro, W. Li, M. Pour-ghaz, P. Huang, J. Weiss, Wetting and drying of concrete using aqueous solutions containing deicing salts, Cem. Concr. Compos. 33 (2011) 535542. doi:10.1016/j.cemconcomp.2011.02.009.

[37] A.V. Wolf, Aqueous Solutions and Body Fluids, Hoeber Medical Division, New York, 1966.

[38] W.J. McCarter, H. Ezirim, M. Emerson, Absorption of water and chloride into concrete, Mag. Concr. Res. 44 (1992) 31-37.

[39] J. Crank, The mathematics of diffusion, second ed., Oxford Science Publication, London, 1975.

[40] S. Sadati, M. Khanzadeh Moradllo, M. Shekarchi, Long-term durability of onshore coated concrete - chloride ion and carbonation effects, 10 (2016) 150-161. doi:10.1007/s11709-0160341-2. 